A N N A L E S Annales de Bretagne et des Pays de l'Ouest

\title{
Les toiles bretagnes dans le commerce franco- espagnol de 1550 à 1830
}

Jean Martin

\section{(2) OpenEdition}

\section{Journals}

Édition électronique

URL : http://journals.openedition.org/abpo/2322

DOI : $10.4000 /$ abpo.2322

ISBN : 978-2-7535-1852-0

ISSN : 2108-6443

Éditeur

Presses universitaires de Rennes

Édition imprimée

Date de publication : 30 mars 2012

Pagination : 31-60

ISBN : 978-2-7535-1850-6

ISSN : 0399-0826

\section{Référence électronique}

Jean Martin, «Les toiles bretagnes dans le commerce franco-espagnol de 1550 à 1830 », Annales de Bretagne et des Pays de l'Ouest [En ligne], 119-1 | 2012, mis en ligne le 30 mars 2014, consulté le 01 mai 2019. URL : http://journals.openedition.org/abpo/2322 ; DOI : 10.4000/abpo.2322 


\title{
Les toiles bretagnes dans le commerce franco-espagnol de 1550 à 1830
}

\author{
Jean MARTIN \\ Docteur en histoire moderne
}

Dès le début du XvI ${ }^{\mathrm{e}}$ siècle, par l'intermédiaire de deux associations de négociants installés en Bretagne, les toiles de la France de l'Ouest ont connu la faveur des différents marchés de la péninsule ibérique. Après 1580, le premier groupement qui unissait Malouins et Vitréens s'est imposé face à ses concurrents espagnols et nantais, en privilégiant l'exportation d'un produit phare ${ }^{1}$, les toiles bretagnes. Il est vrai que ces tissus de lin réalisés entre Saint-Brieuc et Pontivy étaient alors considérés comme de qualité supérieure. Cette faveur a provoqué au XVII ${ }^{\mathrm{e}}$ siècle, dans la zone de production, une croissance de l'activité textile, un accroissement de la population, l'apparition d'une petite bourgeoisie marchande. Alors qu'ils n'étaient à l'origine que de simples compétiteurs sur les marchés andalous, les Malouins ont peu à peu éclipsé les Vitréens et, grâce à leur commerce interlope pendant la guerre de succession d'Espagne (1701-1713), ils ont su détourner une partie des richesses américaines qui transitaient par la Carrera de Indias ${ }^{2}$. Toutefois, avec l'affermissement du pouvoir royal en Espagne, ils ont été amenés à revenir au circuit traditionnel par Cadix. Par la suite, les guerres de la Révolution et de l'Empire, l'indépendance des colonies espagnoles d'Amérique, précédées par l'instauration de nouveaux droits de douane, ont été autant de facteurs qui expliquent, au XIX ${ }^{\mathrm{e}}$ siècle, leur disparition du commerce international et celle de leur zone de tissage du paysage proto-industriel français ${ }^{3}$.

1. Lespagnol, André, "Des toiles bretonnes aux toiles " bretagnes ". Conditions et facteurs d'émergence d'un produit " phare " sur les marchés ibériques ", Revue du Nord, 12,1996, p. 179-192.

2. GARCIA BAQERO, Antonio, La Carrera de Indias, Paris, 1997.

3. MARTin, Jean, Toiles de Bretagne. La manufacture de Quintin, Uzel et Loudéac, 1670 1830, Rennes, 1998. 


\section{Ancienneté des relations entre la Bretagne et l'Espagne}

\section{Par Bilbao, l'intégration de Nantes au commerce castillan}

Les relations commerciales qui unissaient, dès le $\mathrm{xv}^{\mathrm{e}}$ siècle, la Castille et la Bretagne s'inscrivent dans un contexte d'expansion des négociants de la première nation autour du golfe de Gascogne ${ }^{4}$. Il importe aussi de signaler la position d'intermédiaire qu'occupait alors le duché breton sur la route des Flandres, tandis que se prolongeait le conflit opposant la France et l'Angleterre. À l'exemple de l'acte hispano-bourguignon rédigé en 1428 et concernant Bruges, on a vu, deux ans plus tard, le duc de Bretagne conclure un traité de commerce avec les rois de Castille et de Léon. Cet accord, reconduit au cours de la seconde moitié du siècle, et même après la fin de l'indépendance bretonne, portait le titre de Cofradía de la contratación ${ }^{5}$. Il s'agissait d'une régularisation des relations commerciales entre Bilbao et Nantes. Après avoir reconnu le droit d'étape aux importateurs castillans, les autorités bretonnes leur ont accordé une représentation officielle avec un consul et un procureur. Les bonnes relations qui se nouaient ont été complétées ultérieurement par des déductions fiscales portant aussi bien sur les navires que sur leurs cargaisons ${ }^{6}$.

$\mathrm{Au} \mathrm{XvI}{ }^{\mathrm{e}}$ siècle, en dépit de relations parfois tendues entre les cours de France et d'Espagne, Nantes s'est alors imposé comme le principal lieu d'échange des produits espagnols (fer et acier, laines, cire, fruits secs, vins) et français (toiles, draps, céréales) ${ }^{7}$. Le premier quart de ce siècle se caractérise aussi en Castille par un accroissement du nombre d'ovins ${ }^{8}$. Bien que l'élevage transhumant caractérisât l'économie agro-pastorale ibérique, sa croissance fut intimement liée aux besoins exprimés par les différents marchés européens. Une réserve toutefois, celui de Nantes ne pouvait prétendre concurrencer ceux des Flandres.

C'est dans la phase suivante, à partir de 1530, que les relations entre Nantes et Bilbao ont connu un grand développement. Jusqu'en 1553, avec des interruptions dues aux ruptures entre Burgos et Bilbao, chaque année deux flottes quittaient le port de Biscaye, l'une pour La Rochelle et Nantes, l'autre pour Bruges et les Flandres. Bien que Bilbao commercialisât quelques toiles, l'essentiel des cargaisons était acheminé vers Burgos, Medina del Campo et vers les autres foires castillanes.

4. Arízaga Bolumburu, Beatriz, Bochaca, Michel, Tranchant, Mathias, " Aspects du commerce franco-castillan à la fin du Moyen Âge : la progression castillane dans le golfe de Gascogne ", p. 41-42, dans PRIOTTI, Jean-Philippe et SAUPIN, Guy (dir.) Le Commerce atlantique franco-espagnol. Acteurs, négoces et ports (XV'e-XVIII ${ }^{e}$ siècle), Bonchamp-lès-Laval, 2008.

5. Jeulin, Paul, "Aperçus sur la Contratación de Nantes (1530 environ-1733) ", Annales de Bretagne, 1932-1933, p. 284-331.

6. SUAREZ Fernández, Luis, Navigación y comercio en el golfo de Vizcaya, Madrid, 1959, p. 119-120.

7. Touchard, Henri, Le Commerce breton à la fin du Moyen Âge, Paris, 1967; PrIOTTI, JeanPhilippe, "Les produits de l'échange ", dans PrIOTTI, Jean-Philippe et SAUPIN, Guy (dir.), Le Commerce atlantique franco-espagnol..., op. cit., p. 46.

8. Chaunu, Pierre, L'Espagne de Charles Quint, Paris, 1973, t. 1, p. 116, 170, 239 et 244. 
Deux synthèses puisées aux archives du négociant de Burgos, André Ruiz, et concernant ses importations depuis Nantes permettent de se faire une idée plus précise du lien qui l'unissait à Bilbao. Pour la période 15521561 Jean Tanguy a dressé une carte que nous reproduisons ci-après ${ }^{9}$. On découvre que chaque année, en moyenne, 3230 fardeaux ${ }^{10}$ de toiles passaient par les entrepôts nantais des Ruiz : 2358 fardeaux concernaient des toiles de chanvre et 872 des toiles de lin. Les achats provenaient majoritairement du Maine, de l'Anjou, du Poitou, alors que les différents sites armoricains, dont celui entre Saint-Brieuc et Pontivy, n'entraient que pour un quart dans les chargements. On comprend mieux tout l'intérêt stratégique et commercial que constituait alors la Loire en temps de paix.

\section{L'exportation des toiles de la France de l'Ouest}

(Source : TANGUY, Jean, dans SANCHEZ Jean-Pierre [dir.], Dans le sillage de Colomb, Rennes, PUR, 1992, p. 196)

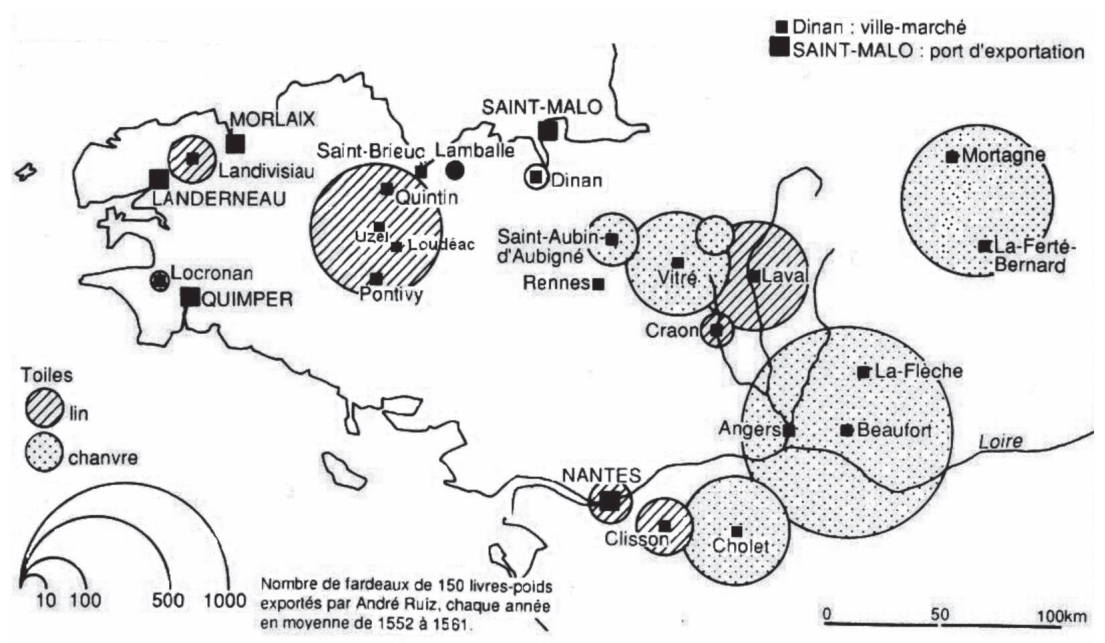

Un article de Jean-Philippe Priotti ${ }^{11}$ synthétise les exportations de toiles depuis Nantes vers Bilbao au cours de la seconde moitié du XvI ${ }^{\mathrm{e}}$ siècle. Quoiqu'ayant emprunté le graphique de cet historien, il a semblé préférable de le transcrire en n'utilisant pas une échelle logarithmique. Ce choix a l'avan-

9. TANGuY, Jean, "L'exportation des toiles de la France de l'Ouest en Espagne dans la seconde moitié du XVI ${ }^{\mathrm{e}}$ siècle ", dans SANCHEZ, Jean-Pierre (dir.), Dans le sillage de Colomb, Rennes, 1992.

10. On peut considérer que les termes fardeaux et balles (colis d'expédition) étaient synonymes dans la manufacture des bretagnes. Les balles contenaient 300 aunes pour les tissus ayant une largeur de 3/4 d'aune et 500 aunes pour ceux de 1/2 aune.

11. PRIOTTI, Jean-Philippe, "Nantes et le commerce atlantique : les relations avec Bilbao au XVI ${ }^{\mathrm{e}}$ siècle ", Annales de Bretagne et des Pays de l'Ouest, 1993, t. 100, p. 265-281. 
tage de mettre en évidence les importantes variations que ce commerce a pu connaître entre 1549 et 1589 . Sans entrer dans le détail, deux périodes apparaissent nettement : la première avant 1568, la seconde jusqu'à 1589. Les fluctuations de la première phase étaient directement liées à la rivalité franco-habsbourgoise mais, comme le constate Jean-Philippe Priotti, " Les échanges [n'étaient pas] encore touchés viscéralement, dans leur structure profonde ». Ultérieurement ce commerce toilier nantais n'a pas su retrouver son dynamisme. La nouvelle situation ne résultait pas seulement de facteurs propres à la France (guerres de religion, course rochelaise, désordres monétaires), ils s'ajoutaient au conflit des Flandres, à la lutte anglo-espagnole, aux problèmes financiers de Philippe II. Dans ces conditions, après 1570, exporter depuis Nantes c'était s'exposer à de maigres bénéfices.

\section{Évolution des exportations par Nantes}

(Source : Priotti, Jean-Philippe, "Nantes et le commerce atlantique : les relations avec Bilbao au XVI siècle ", Annales de Bretagne et des Pays de l'Ouest, 1993,

$$
\text { t. 100, p. 269) }
$$

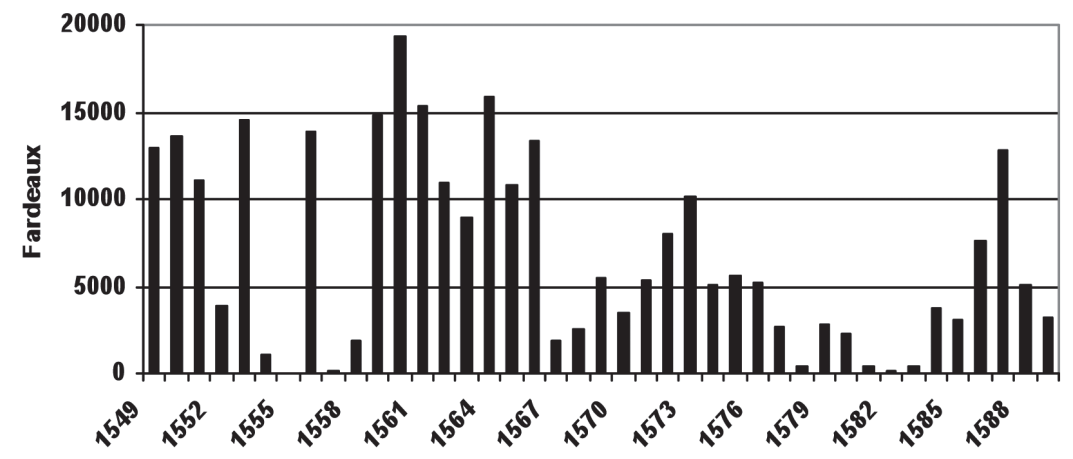

\section{L'intrusion malouine dans le commerce andalou}

Les regards des Malouins ont été longtemps tournés vers les grands centres commerciaux du nord-ouest de l'Europe et, comme le souligne fort justement Henri Touchard ${ }^{12}$, ces marins étaient peu nombreux à descendre vers le sud. Au cours du second tiers du XVI ${ }^{\mathrm{e}}$ siècle $^{13}$, la pêche morutière ${ }^{14}$ qu'ils pratiquaient sur le banc de Terre-Neuve leur a cependant permis de

12. TouchARD, Henri, Le Commerce breton..., op. cit., p. 85, 280.

13. Braudel, Fernand, La Méditerranée et le monde méditerranéen à l'époque de Philippe II, Paris, 1949. Cet historien évoque, p. 472, les navires bretons, anglais, hollandais qui se répandaient sur les côtes espagnoles et portugaises. Il mentionne aussi, p. 166 n. 4, qu'en 1540 à Gibraltar, des pirates algérois avaient pillé deux navires bretons transportant des toiles.

14. Lespagnol, André, "Saint-Malo et l'Espagne. Aperçu Historique d'Ensemble : xve XVIII ${ }^{\mathrm{e}}$ siècles ", Annales de la Société d'Histoire et d'Archéologie de l'arrondissement de Saint-Malo, 1975, p. 146-182. 
fréquenter les ports ibériques de la façade atlantique, avant de pénétrer en Méditerranée. Si le produit séché qu'ils proposaient s'est rapidement imposé sur les marchés portugais et andalous, il s'avérait insuffisant pour espérer intégrer le commerce transatlantique qui commençait à s'épanouir sur les rives du Guadalquivir. À l'initiative des négociants de Vitré, ils ont alors complété leurs cargaisons de poisson par des toiles de la France de l'Ouest ${ }^{15}$. Sans renier leurs accords passés avec les importateurs espagnols qui dominaient ce type de commerce, les Vitréens ont élargi leurs possibilités d'exportation, ajoutant à leurs propres toiles de chanvre une partie de celles qui étaient tissées entre Saint-Brieuc et Pontivy ${ }^{16}$. Cette nouvelle orientation correspondait à des besoins nouveaux, nés de l'élargissement de l'Occident au monde atlantique, avec pour contrepartie l'arrivée des premiers trésors américains ${ }^{17}$.

Les registres de la confrérie des marchands d'Outre-Mer de Vitré nous apprennent qu'au cours de la seconde moitié du XvI ${ }^{\mathrm{e}}$ siècle, certains de ses marchands se sont installés à San Lucar de Barrameda, à Puerto Santa Maria, et à Cadix ${ }^{18}$. Contrairement aux facteurs espagnols des bords de Loire dont les achats visaient avant tout à répondre aux besoins des foires castillanes, une présence française en Andalousie offrait le double avantage de pénétrer le commerce du sud de la péninsule ibérique et de participer plus ou moins directement à La Carrera de Indias qui reliait désormais l'Espagne à ses possessions américaines ${ }^{19}$. Cette installation étrangère en Andalousie, facilitée par le duc de Medina Cela possesseur de grands domaines sur la baie de Cadix, n'était pas du goût de tout le monde. Une analyse de la correspondance des Ruiz met en évidence les conflits que suscitait désormais la concurrence exercée par les Bretons du nord ${ }^{20}$.

15. Frain de LA GAULAYRRIE, Édouard, Les Vitréens et le commerce international, Vannes, 1893.

16. LabBé, Yvonne, "Les débuts d'une ville : Vitré au Xve et Xvi siècle ", Mémoires de la Société d'Histoire et d'Archéologie de Bretagne, t. XXIV, 1944, p. 61-146. On relève, p. 137, la moyenne annuelle des exportations des toiles de chanvre de Vitré dites canevas : 723662 aunes entre 1570 et 1575, 1152890 aunes entre 1575 et 1580, 1345400 aunes en 1586.

17. En 1521 le Pérou avait été découvert, et en 1531 la conquête du Mexique était terminée.

18. Frain de la GaULAYRRIE, Édouard, Cent ans de vie vitréenne, Vitré, 1907, p. 187. GiraRD, André, Le Commerce français à Séville et Cadix au temps des Habsbourgs, Paris, 1932, p. 46, 82; Pennanguer, Anne, "Les Bretons en Andalousie ", dans Martin, Jean et Pellerin, Yvon, Du lin à la toile. La proto-industrie textile en Bretagne, Rennes, 2008, p. 167-178. On relève, p. 175, la mention de "La calle de los Bretones " à San Lucar de Barrameda.

19. DuAult, Martine, La Manufacture et le commerce des toiles bretagnes avec l'Espagne et l'Amérique espagnole du XVI au XVII siècle, mémoire de maîtrise, Rennes 2, 1970, p. 3. Le 10 mai 1511, le navire San Cristobal destiné à Saint-Domingue emportait avec lui 500 vares (une soixantaine d'aunes) de toiles bretonnes.

20. PRIOTTI, Jean-Philippe, « Conflits marchands et intégration économique (Bretagne, Castille et Andalousie, 1560-1580) ", dans PRIOTTI, Jean-Philippe et SAUPIN, Guy (dir.), Le Commerce atlantique franco-espagnol..., op. cit., p. 74 et 78. 
Si la phase 1560-1580 semble déterminante dans la compétition opposant Malouins et Vitréens aux autres exportateurs, elle a aussi été tributaire de la situation nationale et internationale qui a prévalu pendant la plus grande partie de la seconde moitié du XVI ${ }^{\mathrm{e}}$ siècle, impression confirmée par les volumes de sortie du port de Nantes déjà mentionnés auparavant. Les ruptures diplomatiques momentanées avec l'Espagne, l'intervention de pirates rochelais ou anglais dans le golfe de Gascogne, les différentes guerres de religion en France ${ }^{21}$, ont été autant d'éléments défavorables au commerce. À plusieurs reprises Nantes a connu les affres d'une invasion et ses circuits d'approvisionnement ont été maintes fois coupés par des forces hostiles ${ }^{22}$.

En quoi une telle situation pouvait-elle profiter aux Malouins et aux Vitréens? À la différence des négociants de Bilbao qui affrétaient des navires de faible capacité ${ }^{23}$, leurs concurrents bretons utilisaient des navires d'un fort tonnage qui disposaient d'un équipage plus important et, surtout, d'une capacité de feu susceptible de repousser les éventuels assaillants. Le plus déterminant sans doute, c'est qu'ils constituaient de véritables convois, sage précaution qui s'est prolongée tout au long du XVII ${ }^{\mathrm{e}}$ siècle $^{24}$. Il importe aussi de signaler le contexte breton qui a prévalu durant la Ligue ${ }^{25}$. Alors que Nantes et la côte sud de la province accueillaient une flotte et des contingents militaires espagnols, les villes de Rennes, Angers, Vitré, ont été tenues par les royalistes. Un tel contexte ne pouvait que favoriser les exportations par Saint-Malo qui bénéficiait alors d'un statut proche de celui de port franc.

Toutefois une raison semble déterminante dans l'exclusion partielle des importateurs castillans du commerce toilier breton : un mode de paiement différé des tissus provinciaux. Traditionnellement les importateurs espagnols et leurs intermédiaires qui fréquentaient les foires de Pontivy, de Vitré, de Laval, payaient leurs achats à une échéance variant entre 3 et

21. Arch. dép. des Côtes-d'Armor, H 332. Le relevé des dîmes de Saint-Thélo (Côtesd'Armor) apporte des informations sur l'insécurité, la dépopulation et la baisse de la production agricole du centre de la Bretagne, à la fin du XVI ${ }^{\mathrm{e}}$ siècle et au début du XVII ${ }^{\mathrm{e}}$ siècle.

\begin{tabular}{|c|c|c|c|}
\hline Années & Boisseaux & Années & Boisseaux \\
\hline 1595 & 145 & 1609 & 100 \\
\hline 1599 & 50 & 1612 & 103 \\
\hline 1602 & 80 & 1615 & 128 \\
\hline
\end{tabular}

22. LAPEYRE, Henri, Une Famille de marchands, les Ruiz, Paris, 1955, p. 406-419.

23. À ce propos, Henri Lapeyre (Une Famille..., op. cit., p. 424) signale que les navires marchands quittant Nantes disposaient, au mieux, d'un grand navire servant d'escorteur. Simon Ruiz préférait des départs individualisés, ce qui présentait un moindre risque en cas d'attaque des pirates.

24. LesPagnol, André, Messieurs de Saint-Malo. Une élite marchande au temps de Louis XIV, Saint-Malo, 1990, p. 412-419.

25. LE Goff, Hervé, La Ligue en Bretagne. Guerre civile et conflit international (1588-1598), Rennes, 2010. 
7 mois. Ce retard résultait de lettres de change tirées à Medina del Campo et négociables auprès des banquiers lyonnais. Toute différente était la stratégie adoptée par les Malouins et les Vitréens. Le commerce qu'ils pratiquaient en Andalousie se faisait au comptant, et ils revenaient en Bretagne avec de l'argent espagnol pour y faire de nouveaux achats ${ }^{26}$. Les bénéfices suscités par leur activité présentaient deux avantages : l'un résultait tout naturellement de leurs ventes et l'autre du change qu'ils pratiquaient en France. On constate en effet que, jusqu'en 1577, la monnaie nationale s'est régulièrement dépréciée face au réal espagnol.

Dans l'opposition que nous venons de relater, on ne peut faire abstraction d'un retrait partiel de la firme Ruiz du commerce pratiqué à Nantes. Jean-Philippe Priotti ${ }^{27}$ a mis en évidence les modifications de stratégie qui ont alors affecté ce puissant groupe ${ }^{28}$. Cela s'est traduit par le remplacement des intermédiaires nantais au profit de collaborateurs basques ou castillans plus dociles. Cette substitution a provoqué une faiblesse du réseau et la quasi-impossibilité de s'adapter à de nouvelles conditions. Une telle phase de recentrage s'est déroulée en une période où Simon Ruiz réorientait sa maison de commerce vers le domaine bancaire et privilégiait ses relations avec les Flandres plus susceptibles de lui fournir un meilleur rapport. Il faut aussi prendre en considération la destination des produits exportés. Les importateurs espagnols destinaient majoritairement leurs toiles aux couches sociales intermédiaires et urbaines de Castille, alors que Malouins et Vitréens commençaient à intervenir sur le marché colonial américain $^{29}$. Cette pénétration a été facilitée par l'union commerciale qui s'est instaurée dans le dernier quart du XVI ${ }^{\mathrm{e}}$ siècle entre les Vitréens présents à Cadix et les Peruelos. On désignait par ce terme les Péruviens porteurs de métaux précieux susceptibles d'honorer immédiatement les commandes

26. Lapeyre, Henri, Une Famille..., op. cit., p. 524, rapporte qu'en 1584 les Vitréens avaient ramené d'Espagne 200000 écus. En 1591, où « La descente des Anglais à Paimpol causa d'abord une grande alarme aux Malouins, dans la crainte qu'ils eurent que la flotte anglaise n'allât tomber sur leurs vaisseaux qui revenaient d'Espagne chargés de 500000 écus. Cela les obligea d'envoïer au devant deux pataches qui les ayant heureusement rencontrés les firent relâcher à Blavet [Port-Louis] où ils reçurent toutes sortes de bons traitements des Espagnols. Non obstant qu'ils sçussent que tout cet argent était tiré de leur païs contre les défenses expresses ", Arch. mun. de Saint-Brieuc, Ms 23, $\mathrm{f}^{\circ} 153 \mathrm{r}^{\circ}$.

27. PRIOTTI, Jean-Philippe, "Conflits marchands et intégration économique (Bretagne, Castille et Andalousie, 1560-1580) ", dans PRIOTTI, Jean-Philippe et SAUPIN, Guy (dir.), Le Commerce atlantique franco-espagnol..., op. cit., p. 85-87 et "Logiques commerciales d'une globalisation. Les toiles françaises dans l'Atlantique hispano-américain (1550-1600) ", dans Perez, Béatrice, Rose, Sonia, CléMent, Jean-Pierre, Des Marchands entre deux mondes. Pratiques et représentations en Espagne et en Amérique, Paris, 2007, p. 15-41.

28. On peut aussi relever une certaine xénophobie nantaise à l'égard des marchands étrangers, voir SAUPIN, Guy, « Le privilège comme réponse à la concurrence commerciale étrangère : Nantes au début du XVII ${ }^{\mathrm{e}}$ siècle ", Annales de Bretagne et des Pays de Loire, t. 117, 2010, p. 75-90.

29. García Baquero Gonzales, Antonio, La Carrera de Indias..., op. cit., p. 154. On peut lire qu'en 1584 et 1598, la part des différents textiles représentait $60 \%$ dans les cargaisons destinées aux Indes occidentales. 
qu'ils passaient, au contraire des cargadores (chargeurs) sévillans. En effet, ces derniers, accompagnateurs traditionnels des différentes expéditions destinées aux colonies américaines, ne pouvaient rendre compte de leurs ventes qu'au retour des escadres, c'est-à-dire au bout d'une année ou deux.

Toutefois, en comparaison avec les différentes toiles de la France de l'Ouest exportées vers l'Espagne $\mathrm{au} \mathrm{XVI}^{\mathrm{e}}$ siècle, la part des bretagnes demeurait encore modeste ${ }^{30}$. Un document plus tardif, puisque daté de $1751^{31}$, évoque la situation de cette manufacture au début du XVII ${ }^{\mathrm{e}}$ siècle : " Au commencement du dernier siècle il se fabriquait encore bien peu de ces toiles par comparaison à ce qui s'en fait aujourd'hui [...]. Il n'y avait que douze marchands dans cette fabrique dans ces temps éloignés ${ }^{32}$. " À propos du Pérou il est aussi indiqué que " des négociants de cette nation [l'Espagne] y portèrent quelques pacotilles de toiles de Quintin [...] mais la consommation était encore bien médiocre attendu qu'ils [les Péruviens] étaient dans l'usage de porter des chemises de laine, chose dont ils ne se sont déshabitués que par la suite».

Il aurait été intéressant de retrouver ce que fut vraiment le développement de la toilerie en Bretagne centrale sous influence malouine, au cours de la première moitié du XVII ${ }^{\mathrm{e}}$ siècle. Les documents font hélas défaut et seuls quelques éléments souvent anecdotiques nous sont parvenus.

Le premier concerne une évolution de la culture du lin dans la région de Tréguier, zone qui a toujours fourni la matière première dont les tisserands de la Bretagne centrale avaient besoin, leur sol étant trop pauvre pour la produire ${ }^{33}$. Jusque dans les années 1590, les paysans des paroisses proches de La Manche cultivaient une plante indigène, le lin breton qui n'atteignait guère plus d'un pied de hauteur à maturité. Il en est allé tout autrement avec l'introduction de la linette flamande importée depuis le port de Roscoff et qui atteignait 3 à 4 pieds. Le premier tiers du XVII ${ }^{\mathrm{e}}$ siècle a donc vu surgir, dans l'évêché de Tréguier, de très nombreux procès à propos du prélèvement de la dîme sur la nouvelle fibre. Ces différends permettent d'apprendre qu'entre 1600 et 1655 la livre de fil de lin est passée de 5 sols à 15 sols. L'accroissement observable dans ce prix ne reflétait pas celui des produits agricoles traditionnels multipliés par deux pendant la même période, il résultait d'une demande extérieure en pleine croissance.

30. TANGUY, Jean, " La production et le commerce des toiles bretagnes du XVI ${ }^{\mathrm{e}} \mathrm{au}$ XVIII ${ }^{\mathrm{e}}$ siècle ", Actes du Quatre-vingt-onzième Congrès National des Sociétés savantes, Paris 1969, p. 108-109. En 1592 Saint-Malo avait vu transiter 51 fardeaux de " pontivis ", 16 fardeaux 1/4 de "bretagnes ", une centaine d'aunes de "quintines " et, en 1594, alors que le total des différentes toiles bretonnes expédiées depuis Séville vers l'Amérique s'élevait à 980170 " vares ", la part des bretagnes ne s'élevait qu'à 3035 vares.

31. Arch. dép. d'Ille-et-Vilaine, C 3929, rapport de l'inspecteur des manufactures, de Coisy, en 1751.

32. TANGUY, Jean, "La production et le commerce des toiles bretagnes du XVI ${ }^{\mathrm{e}} \mathrm{au}$ XVIII ${ }^{\mathrm{e}}$ siècle ", loc. cit., p. 109.

33. MinoIs, Georges, Un Échec de la réforme catholique en Basse-Bretagne : Le Trégor du XVI ${ }^{e}$ au XVIII siècle, Thèse de doctorat, univ. Rennes 2, 1984, p. 108-120. 
Des contestations relatives à la législation des domaines congéables ${ }^{34}$ dans la région d'Uzel permettent de découvrir un second élément qui prouve l'enrichissement de certains marchands de toiles du centre de la Bretagne. C'est ainsi qu'en $1649^{35}$, une expertise concernant des édifices nouvellement bâtis a été conduite par les officiers de cette seigneurie. Leur compte rendu rapporte l'évolution constatée en ces termes : "Il est venu à nouvelle connaissance que beaucoup de particuliers, sujets et convenanciers des terres et seigneurie dudit Uzel [...] se sont permis [...] (de) bâtir, construire et édifier sur les fonds et domaines dudit seigneur y employant pour fenêtre lucarnes et cheminées des tailles de pierre de grain. Non content de ce, les font couvrir de pierres et ardoises vertes, font des cours à portes cochères. " Pour quatre paroisses mentionnées ${ }^{36}$, les juges locaux ont noté que les infractions concernaient 35 maisons, 21 dépendances, 5 murailles extérieures. Si en majorité les nouvelles propriétés avaient de 30 à 40 pieds de long, quatre présentaient une façade plus importante, associant sous le même toit le foyer du propriétaire et un espace voué à l'activité agricole. Tous ces édifices se différenciaient du bâti traditionnel, puisqu'ils disposaient d'un étage, de plusieurs cheminées, enfin d'une tourelle qui abritait un escalier en colimaçon permettant d'accéder aux chambres. Alors que la législation en vigueur aurait dû conduire à détruire ces constructions, leurs propriétaires ont obtenu l'indulgence des officiers seigneuriaux en acquittant une amende proportionnelle à la valeur de leurs constructions ${ }^{37}$.

\section{La manufacture des bretagnes}

\section{Un espace proto-industriel}

Jusqu'à la fin du Xvie siècle, on peut considérer que deux pôles principaux de production et de commercialisation dominaient : Pontivy et Quintin. Les grandes foires régionales ${ }^{38}$ qui se tenaient aux abords de la première cité favorisaient le transfert des diverses productions vers Nantes et, à un degré moindre, vers Saint-Malo et Morlaix. La modification du circuit nantais a réduit l'influence de Pontivy au profit de celle de Quintin.

34. Ce statut du sol, propre à la Bretagne, et qui s'est prolongé après la Révolution, interdisait de construire des édifices susceptibles d'être confondus avec des manoirs nobles par leur taille, leur hauteur, l'encadrement des huisseries, leur tourelle, enfin par l'utilisation d'ardoises.

35. Archives privées, descendants Boschat.

36. Uzel, Le Quillio, Saint-Thélo, Saint-Martin-des-Prés.

37. Les autres paroisses rurales semblent avoir connu le même phénomène d'enrichissement des petits marchands locaux de toiles, puisque l'on relève, pour la même période, 4 nouvelles constructions à Allineuc, 5 à Loudéac, 6 à Merléac, 4 à Saint-Caradec, 5 à Saint-Guen, 7 à Trévé.

38. TANGUY, Bernard, " Les foires franches de Noyal-Pontivy au Moyen Âge ", Association Bretonne, 2003, p. 555-571. 
Par la suite, un accroissement de la demande malouine a favorisé une extension du tissage entre Quintin et Loudéac, zone aux revenus agricoles médiocres ${ }^{39}$. On observe une croissance de la population dans les paroisses qui s'adonnaient alors au tissage ${ }^{40}$. Ainsi, entre 1667 et 1696 , les petites cités de Loudéac et d'Uzel sont-elles passées de 25 et 50 habitants au $\mathrm{km}^{2}$ à 75 et à $200^{41}$, Devenir tisserand conférait une autonomie que ne pouvait procurer l'activité agricole traditionnelle où l'individu était tributaire, dans la gestion de son entreprise, de la disparition de ses géniteurs. La liberté, toute relative, que se voyait alors octroyer le tisserand, lui permettait de décider de son destin. Cela s'est traduit par une précocité de l'âge au mariage et par une descendance plus prolifique ${ }^{42}$.

De tous les artisans de la manufacture, le plus apprécié était le tisserand, la qualité de sa production étant recherchée par les consommateurs espagnols et américains ${ }^{43}$. Les différents inspecteurs des manufactures qui ont eu pour fonction de surveiller ces ouvriers après 1676 ont toujours éprouvé de grandes difficultés à les recenser. En 1719 l'inspecteur des manufactures, Caillaud, estimait qu'il était impossible de connaître leur nombre exact, et son successeur, Le Marchand, écrivait cinq ans plus tard : "Il faudrait plus de trois ans à un seul homme pour faire le dénombrement ${ }^{44}$. " C'est que le terme tisserand, quoique d'usage pratique, recouvrait des situations différentes. Il pouvait concerner un citadin ou un rural, un artisan à temps complet ou un accidentel, un travailleur indépendant ou un prolétaire façonnier. Des statistiques réalisées au début du XVIII ${ }^{\mathrm{e}}$ siècle et concernant les ouvriers de Quintin ${ }^{45}$ nous apprennent qu'avec une moyenne de 500 tisserands la ville était alors le principal centre de la manufacture. Toutefois, au cours de ce siècle, la zone comprise entre Uzel et Loudéac a connu une forte croissance de l'activité toilière, au point qu'on y recensait les deux tiers des ouvriers de la manufacture au début de la Révolution ${ }^{46}$.

\section{Une bourgeoisie locale sous influence}

Comme la plupart des artisans locaux ne pouvaient se déplacer à SaintMalo pour y vendre leurs productions, le nombre des marchands de toiles s'est accru. Ces intermédiaires se chargeaient aussi bien de faire blanchir

39. MARTin, Jean, Toiles de Bretagne. La manufacture de Quintin..., op. cit., p. 35-52.

40. Arch. dép. des Côtes d'Armor, H 32, à Saint-Thélo en 1697, une contestation à propos de la dîme signale que l'augmentation de la population nécessitait d'adjoindre un nouvel ecclésiastique au recteur.

41. Croix, Alain, La Bretagne aux $16^{e}$ et $17^{e}$ siècles, Paris, 1981, t. 1, p. 126, 127.

42. Martin, Jean, Toiles de Bretagne..., op. cit., p. 225. Pour les décennies 1679-1688 et 1689-1698 on observe que les rapports baptêmes/mariages étaient de 5,09 et 5,29, et ceux des baptêmes/sépultures de 1,18 et 1,25.

43. Archives de la Marine, Paris, B 7/495, fol. 54, 11 juillet 1688, « Les Espagnols sont si satisfaits qu'ils prétendent en former la plupart de leurs cargaison. "

44. Arch. nat., $\mathrm{F}^{12} 555,1417$.

45. Arch. mun. de Quintin, HH 2.

46. Arch. dép. d'Ille-et-Vilaine, C 1534, 3929. 
les tissus ${ }^{47}$, comme l'exigeaient les consommateurs hispaniques, que de les préparer à la vente. Après diverses manipulations, des balles (colis de 300 ou 500 aunes) étaient constituées et les marchands les transportaient jusqu'à Saint-Malo devenu principal port exportateur. Jusqu'au début du XVIII ${ }^{\mathrm{e}}$ siècle, ceux qui pratiquaient le commerce des toiles bretagnes à SaintMalo utilisaient, après leur visite au Consulat, les services d'intermédiaires chargés de les introduire chez les négociants locaux ${ }^{48}$. Cette infériorité du monde de la production apparaît au travers des deux règlements appliqués à la manufacture en 1676 et 1736 . Bien que l'autorité royale ait laissé croire à une intervention seulement motivée par " le peu de soin et de fidélité que les tisserands apportent dans leur manufacture [...] à cause du grand débit quy sen fait dans les pays etrangers ${ }^{49}$ ", elle confortait une demande des exportateurs malouins ${ }^{50}$. Dans la concurrence que ceux-ci rencontraient à Cadix, il importait de présenter un produit fiable aux acquéreurs $^{51}$. L'éloignement entre le port de la Rance et la manufacture ne favorisant guère la surveillance des lieux de production, on a donc vu leur principal effort se porter sur les marchands quintinais. La petite ville, qui concentrait initialement près du quart des ouvriers, présentait aussi l'avantage d'abriter de nombreux marchands. Les plus représentatifs ont alors été choisis pour animer le bureau de marque des toiles, y accepter ou refuser les produits qui leur étaient proposés. Leur contrôle s'est avéré plus déterminant que les visites épisodiques de l'inspecteur des manufactures. Il a cependant fallu attendre 1736, et l'application d'un nouveau règlement, pour qu'un sous-inspecteur fût nommé à Quintin, y exerçât sa surveillance, de même qu'à Uzel et Loudéac, autres lieux où se tenaient aussi des marchés aux toiles.

L'analyse de trois années de capitation concernant Quintin ${ }^{52}$ permet de retrouver la montée en puissance d'une petite élite marchande au $\mathrm{XVIII}^{\mathrm{e}}$ siècle. Alors que seuls trois marchands quintinais payaient plus de 60 livres en 1720, ils étaient cinq en 1740 et onze en 1750. Si quelques documents évoquent leur participation au commerce avec Cadix, voire avec l'Amérique, les bénéfices réalisés n'étaient guère réinvestis dans leur principale activité ${ }^{53}$. C'est qu'ils ont été de grands bâtisseurs. On a vu apparaître de véritables hôtels particuliers à Quintin dans les faubourgs de

47. Les marchands coupaient leurs pièces à la longueur de 5 aunes ou 8 vares d'Espagne, car cette longueur correspondait à la mesure destinée à la fabrication des chemises sur les marchés espagnols et américains.

48. Arch. dép. de Loire-Atlantique, C 697.

49. Arch. mun. de Quintin, BB 5, lettres de créance de l'inspecteur Collart en 1687.

50. Arch. dép. d'Ille-et-Vilaine, C 1531, pour Éon de la Ville-Bague et Noël du Fougerais en 1676. Arch. mun. de Quintin, BB 21, pour Moreau de Maupertuis en 1734.

51. Morineau, Michel, Incroyables Gazettes et Fabuleux Métaux, Cambridge-Paris, 1985, p. 331. Pour la seconde moitié du XVIII ${ }^{\mathrm{e}}$ siècle, voir ZYLBERBERG Michel, Une si douce domination. Les milieux d'affaires français et l'Espagne vers 1780-1808, Paris, 1993.

52. Arch. dép. de Loire-Atlantique, C 3584, 3594, pour 1720 et 1750 . Arch. dép. d'Ille-etVilaine, C 4099, pour 1740.

53. MARTin, Jean, Toiles de Bretagne..., op. cit., p. 255-271. 
Saint-Thurian et des Croix-Jarots. En se rapprochant du mode de vie de la noblesse, la bourgeoisie locale a été tentée d'y pénétrer, que ce soit par le mariage de ses filles ou en achetant une charge de secrétaire du roi. Il serait excessif de laisser croire que le phénomène a seulement touché Quintin, les plus importants marchands d'Uzel, de Loudéac, mais aussi des paroisses rurales, ont été sensibles aux propriétés des négociants malouins du ClosPoulet. Enfin, les possibilités financières de l'élite marchande entre Quintin et Loudéac lui ont aussi permis de se substituer à une petite noblesse locale souvent désargentée. Au début du XIX ${ }^{\mathrm{e}}$ siècle, 26 héritiers quintinais disposaient toujours de propriétés estimées à 50 hectares, et 16 d'entre eux avaient plus de 100 hectares $^{54}$.

\section{Les toiles bretagnes dans le commerce hispano-américain}

\section{La période d'affermissement 1660-1698}

Les liaisons entre l'Espagne et l'Amérique latine ont été longtemps rythmées par les arrivées et les départs de "La Carrera de las Indias del Mar Oceano $^{55}$ ". L'ensemble formait un puissant système maritime et mercantile reposant sur une véritable toile d'araignée. Si les soutes des navires espagnols contenaient divers produits essentiels, les chargements étaient majoritairement constitués d'étoffes. La Carrera présentait deux options : l'une reliait la Nouvelle-Espagne (Veracruz, La Trinité, Curaçao, La Havane, Campêche) et l'autre la Terre Ferme (Carthagène et Portobello). En dehors de ces circuits officiels, il existait d'autres alternatives pour commercer avec les Indes Occidentales. Des navires disposant de libres registres pouvaient être autorisés à fréquenter quelques ports situés en dehors des routes habituelles. De même, tout navire quittant l'Espagne pouvait servir aux exportateurs, ce qui les conduisait à utiliser aussi bien les courriers maritimes que les transports de mercure.

Même si les liaisons régulières étaient programmées tous les deux ans, l'engorgement du marché américain et les multiples risques maritimes rencontrés ont conduit, entre 1669 et 1684, à une évolution vers la triennalité. Il est des années où les départs ont été retardés, voire interdits ${ }^{56}$. Selon les informations recueillies par l'inspecteur français Patoulet envoyé en mission à Cadix en $1686^{57}$, les différentes productions européennes destinées aux colonies espagnoles étaient estimées à un peu plus de 43 millions de piastres (27 millions pour la Terre Ferme, 16 millions pour la

54. Synthèse obtenue grâce aux cadastres réalisés au début du XIX ${ }^{\mathrm{e}}$ siècle entre SaintBrieuc et Loudéac. On ne peut négliger cependant que certains achats aient été réalisés à la faveur de la Révolution, bien que l'action des bandes chouannes ait souvent empêché les transferts de propriété.

55. GiRARD, André, Le Commerce français à Séville et Cadix au temps des Habsbourgs, Paris, 1932, p. 7-10. García Baquero Gonzalves, Antonio, La Carrera de Indias..., op. cit., p. $66-80$.

56. MORINEAU, Michel, Incroyables gazettes..., op. cit., p. 267-275.

57. BnF, site de l'Arsenal, ms 4068. 
Nouvelle-Espagne). Les importations françaises représentaient 17 millions de piastres, dont 10 millions pour les seuls tissus. Indéniablement la France était le premier partenaire économique de l'Espagne.

L'intrusion commerciale française en Espagne a connu un fort accroissement au cours de la première moitié $\mathrm{du} \mathrm{XVII}^{\mathrm{e}}$ siècle, la guerre de Trente Ans (1618-1648) ayant temporairement exclu les toiles silésiennes au profit des bretagnes. Par la suite, le traité des Pyrénées (1659), qui mettait fin au conflit franco-espagnol, a été chaleureusement accueilli à Quintin ${ }^{58}$. Il est vrai que dans son article vi il faisait de la France, la nation la plus favorisée : alors que les droits de douane étaient généralement élevés, les productions bretonnes n'étaient soumises qu'à 2 sols 4 deniers par aune large, et 1 sol 9 deniers pour les étroites ${ }^{59}$. Cet avantage, qui s'est prolongé jusqu'en 1779, leur a permis de s'imposer sur les marchés andalous. Avec le transfert partiel puis définitif à Cadix de la Casa de Contratacion est apparu un pôle gaditan qui regroupait autour du port principal ceux de San Lucar de Barrameda et de Puerto Santa Maria. Ce vaste espace nautique a vu s'installer sur ses rives de nouveaux négociants français, et parmi ceux-ci les commissionnaires des plus grandes maisons malouines ${ }^{60}$. Toutefois, de toutes les causes qui attiraient les négociants étrangers en Espagne, c'est bien l'attrait des trésors américains qui demeurait la motivation essentielle. Michel Morineau a d'ailleurs fourni une évaluation quinquennale des retours de métaux précieux américains de 1650 à $1699{ }^{61}$.

\section{Retours monétaires d'Amérique}

\begin{tabular}{|c|c|c|c|}
\hline Période & Millions de piastres & Période & Millions de piastres \\
\hline $1650-1654$ & $39(?)$ & $1675-1679$ & 84,5 \\
$1655-1659$ & 51,6 & $1680-1684$ & 51,5 \\
$1660-1664$ & 65 & $1685-1689$ & 78 \\
$1665-1669$ & 61,3 & $1690-1694$ & 81,8 \\
$1670-1674$ & 87 & $1695-1699$ & 65,5 \\
\hline
\end{tabular}

Bien que de grandes variations puissent être observées dans les sommes rapportés, elles sont loin de justifier l'état dépressionnaire du commerce espagnol qui a été souvent évoqué. Tenter de prendre en compte la pénétration commerciale étrangère dans le grand flux de la Carrera conduit tout naturellement à évoquer les phénomènes de corruption qui la caractérisaient ${ }^{62}$. La fraude commençait à l'arrivée des marchandises, les Espagnols ne pouvant monter à bord des navires sans l'autorisation du

58. Arch. mun. de Quintin, D 15.

59. Ibid., F 19.

60. LESPAGNol, André, Messieurs de Saint-Malo..., op. cit., p. 835.

61. MORINEAU, Michel, Incroyables gazettes..., op. cit., p. 262.

62. SÉE, Henri, « Documents sur le commerce de Cadix ", Revue de l'Histoire des Colonies Françaises, 1926, p. 465-520. 
consul de la nation à laquelle ils appartenaient. En différant de répondre immédiatement à la demande qui lui était faite, le consul permettait d'effectuer un débarquement illicite. De plus, les cargadores (chargeurs), délégués commerciaux des différentes escadres, auraient dû normalement servir de représentants aux seules maisons espagnoles; or la plupart se transformaient en intermédiaires des maisons étrangères ${ }^{63}$. La corruption existait aussi en Nouvelle-Espagne ${ }^{64}$ et sur la Terre Ferme, tout comme elle se répétait avec le retour des navires chargés de métaux précieux. C'est pour réduire l'importance de ces trafics illégaux qu'une série de taxes, les Indults, fut imposée au commerce transatlantique. Dans le grand maelström commercial que constituait la baie de Cadix, quelle part les toiles françaises occupaient-elles ${ }^{65}$ ? Le rapport de Patoulet répond à cette interrogation :

\section{Le commerce des toiles de l'Ouest avec l'Espagne et ses colonies}

\begin{tabular}{|c|c|c|c|c|c|c|}
\hline Province & $\begin{array}{l}\text { Zone de } \\
\text { production }\end{array}$ & $\begin{array}{l}\text { Types de } \\
\text { toile }\end{array}$ & $\begin{array}{c}\text { Espagne } \\
\text { (valeur en } \\
\text { livres) }\end{array}$ & $\begin{array}{c}\text { Nouvelle- } \\
\text { Espagne } \\
\text { (livres) }\end{array}$ & $\begin{array}{l}\text { Terre-Ferme } \\
\text { (livres) }\end{array}$ & $\begin{array}{c}\text { Total } \\
\text { (livres) }\end{array}$ \\
\hline Maine & Laval & $\begin{array}{l}\text { Basse laise } \\
\text { Haute laise }\end{array}$ & 400000 & 300000 & 450000 & $\begin{array}{r}400000 \\
\underline{750000} \\
1150000\end{array}$ \\
\hline Bretagne & $\begin{array}{l}\begin{array}{l}\text { De Quintin à } \\
\text { Pontivy } \\
\text { (bretagnes) }\end{array} \\
\begin{array}{l}\text { Léon/Trégor } \\
\text { (crées) }\end{array} \\
\begin{array}{l}\text { Haute Bre- } \\
\text { tagne }\end{array}\end{array}$ & \begin{tabular}{|l} 
Ordinaires \\
Larges \\
\\
Communes \\
Graciennes \\
Larges \\
\\
\\
Dinan \\
Fougères \\
Noyales \\
Vitré
\end{tabular} & $\begin{array}{c}300000 \\
375000 \\
\\
1000000 \\
60000 \\
180000 \\
\\
\\
35000 \\
60000 \\
36000 \\
10000\end{array}$ & $\begin{array}{l}900000 \\
375000\end{array}$ & $\begin{array}{l}1800000 \\
1000000\end{array}$ & $\begin{array}{c}3000000 \\
\frac{175000}{4750000} \\
1000000 \\
60000 \\
\underline{360000} \\
1420000 \\
35000 \\
60000 \\
36000 \\
\underline{10000} \\
141000 \\
6311000\end{array}$ \\
\hline TOTAL & & & 2456000 & 1755000 & 3250000 & 7461000 \\
\hline
\end{tabular}

63. Archives de la Marine, Paris, $B^{7} 492$. En 1686, le Malouin Du Val Le Fer pouvait écrire à Seignelay : "Tous les effets qu'ils [Les Malouins] ont sur les Galions et autres navires que l'on attend des Indes y ont été chargés sous le nom des Espagnols. " Michel MoRINEAU (Incroyables gazettes... op. cit., p. 270) signale que les négociants français n'envoyaient en Amérique que les deux tiers de leurs marchandises. En écho, André LEsPAGNOL (Messieurs de Saint-Malo..., op. cit., p. 466), souligne que les Malouins de Cadix agissaient de même, sauf pour les liaisons avec Buenos-Aires.

64. GARCía de LEÓN, Antonio, "Contrabando y comercio del rescate en el Veracruz del siglo XVII ", dans YUSTE, Carmen, Comercio marítimo comercial colonial. Nuevas interpretaciones y ultimas fuentes, México, 1997, p. 30.

65. SÉE, Henri "Documents sur le commerce de Cadix ", loc. cit., p. 492. BnF, Bib. de l'Arsenal, ms 4068. Rapport de PAtoulet. 
Une comparaison de ce tableau avec la carte de Jean Tanguy fait apparaître des modifications dans l'importance des différentes zones de tissage. La toilerie de la France de l'Ouest a connu un grand essor au cours du XVII ${ }^{\mathrm{e}}$ siècle, Patoulet l'estimant à 48,54 \% des tissus français expédiés à Cadix, mais on observera aussi le recul des toiles de chanvre, certaines disparaissant et d'autres ne représentant plus que $2 \%$ des envois. Les productions de Laval ${ }^{66}$ ont été intégrées à ce tableau car les négociants de cette ville faisaient appel aux Malouins pour exporter leurs toiles. La relative importance des crées du Léon (19\% de l'ensemble) s'explique par d'autres destinations que l'Andalousie ${ }^{67}$. Indéniablement c'est l'espace entre Saint-Brieuc et Loudéac qui a connu la plus forte croissance de son tissage. Il est aussi intéressant d'observer la ventilation des toiles à partir de l'Andalousie : un tiers pour le marché espagnol, le reste pour les colonies américaines. Alors que très souvent les marchés de Nouvelle-Espagne étaient victimes d'un engorgement des productions européennes, la faveur des bretagnes semble s'être maintenue plus régulièrement en Terre Ferme. D'ailleurs Michel Morineau ${ }^{68}$ signale qu'entre 1661 et 1699, à Portobello, le commerce a connu six bonnes foires et deux mauvaises. Au contraire, à Veracruz il n'a relevé que trois bonnes foires pour quatre mauvaises.

Les bénéfices réalisés dans le cas d'une vente en Espagne pouvaient être estimés entre 12 et $15 \%$, tandis qu'une expédition aux Indes Occidentales atteignait de 25 à $30 \%$. Toutefois, les différentes contraintes qui pesaient sur les négociants bretons installés en Andalousie les ont souvent conduits à n'expédier pour leur compte qu'un tiers des toiles qu'ils réceptionnaient. Pour le reste comme le confirme par Patoulet : "Nos toiles [...] sont si nécessaires pour ce commerce [avec l'Amérique] et celuy d'Espagne que tous les estrangers nos voisins qui y envoyent des marchandises sont obligez pour pouvoir vendre celles de la fabrique et du crû de leurs Estats, d'en assortir leurs carguaisons et qu'enfin [...] elles donnent le prix et la valeur à toutes les autres marchandises."

Au niveau régional, les principaux bénéficiaires du commerce avec l'Espagne ont été les grands négociants malouins. De la paix des Pyrénées à l'automne 1688, ils ont chargé en toute illégalité sur leurs frégates une part importante des lingots d'argent que leurs ventes procuraient en Amérique. En 1688 Magon de la Lande recevait 100000 piastres pour sa participation à l'expédition de Nouvelle-Espagne ${ }^{69}$. À partir de 1689, la présence de navires hostiles dans l'Atlantique ou dans la Manche a conduit les négociants français à dérouter leurs vaisseaux chargés de métal précieux vers Marseille puis Gênes ${ }^{70}$. Il est une dernière forme d'intéressement que les

66. DloussKy, Josseline, Jacques Hoisnard, négociant ou le commerce des toiles à Laval au XVII e siècle, Thèse, univ. Rennes 2, 1988, 2 vol.

67. TANGuY, Jean, Quand la toile va, Rennes, 1994, p. 77-79. Les toiles " crées " étaient majoritairement destinées à l'Angleterre.

68. Morineau, Michel, Incroyables gazettes..., op. cit., p. 294.

69. Lespagnol, André, Messieurs de Saint-Malo..., op. cit., p. 470.

70. Arch. nat., Marine, B7/496, $\mathrm{f}^{\circ} 13$. 
Malouins pratiquaient, celle d'intermédiaires obligés entre Saint-Malo et Cadix. En acquérant une part des toiles qui transitaient par leur port, ils devenaient, grâce à leurs entrepôts gaditans, les fournisseurs essentiels de l'Espagne et de ses colonies. André Lespagnol ${ }^{71}$ précise qu'une expédition de 10000 livres de toiles pouvait procurer un bénéfice de 1650 livres, grâce aux seules consignations et commissions.

La situation s'est profondément modifiée à partir de 1689, avec la rupture des relations diplomatiques entre la France et l'Espagne. Les expulsions de Malouins se sont accompagnées d'une confiscation de leurs marchandises et ceux qui souhaitaient rester en Andalousie n'ont eu d'autre solution que de se réfugier dans des couvents ${ }^{72}$.

\section{Le commerce interlope 1698-1720 ${ }^{73}$}

Les dernières décennies du XVII ${ }^{\mathrm{e}}$ siècle se caractérisent, pour le commerce hispano-américain, par de profondes perturbations. Les îles des Antilles sont devenues une zone marginale et mal contrôlée, un maillon faible au sein de l'empire colonial, situation qui a favorisé une pénétration étrangère. Ce contexte a été mis à profit par des flibustiers pratiquant aussi bien des transactions de faible importance que le " commerce à la longueur de la pique ". Antonio García de León ${ }^{74}$ a pu les identifier au Mexique. Les plus nombreux semblent avoir été des créoles portugais qui utilisaient tout un petit monde d'intermédiaires composé d'indiens hispanisés, de pêcheurs flamands, andalous ou genevois. Les ruptures d'accord, les dénonciations, étaient autant d'éléments qui suscitaient des actions violentes, comme celle du Hollandais, Laurent de Graaf, qui investit Veracruz en 1683. Sa connaissance des commerçants locaux lui permit de les dépouiller de leur or et de leur argent.

La voie que les pirates avaient ouverte a été suivie par les gouvernements de Hollande et d'Angleterre. Curaçao et la Jamaïque sont devenus des entrepôts destinés au marché américain ${ }^{75}$. Les Malouins qui, jusqu'alors privilégiaient la voie gaditane, ont aussi fait appel à certains navires de ces deux nations pour des exportations frauduleuses de toiles ${ }^{76}$. Les profits réalisés les ont conduits à utiliser les possessions françaises de Saint-Domingue et des Antilles comme entrepôts ${ }^{77}$. Toutefois, selon André

71. Lespagnol, André, Messieurs de Saint-Malo..., op. cit., p. 456.

72. Arch. Nat., Marine, $B^{7} 497, f^{\circ} 280$.

73. DAHLGREN, Erik, Wilhelm, Les Relations commerciales et maritimes entre la France et les côtes de l'Océan Pacifique, t. 1, Le commerce de la Mer du Sud jusqu'à la paix d'Utrecht, Paris, 1909.

74. GARCía de LEón, Antonio, "Contrabando y comercio de rescate en el Veracruz del siglo XVII ", op. cit., p. 28.

75. Arch. nat., Marine, $\mathrm{B}^{7} 492, \mathrm{f}^{\circ}$ 249-250.

76. Arch. dép. d'Ille-et-Vilaine, 9B/453.

77. Ibid., 9B/451. 
Lespagnol on ne peut parler, à propos de ces relais, que d'un petit « interlope insulaire de proximité ${ }^{78} "$.

Les contextes politiques et économiques qui ont accompagné et suivi la guerre de la ligue d'Augsbourg (1688-1697) se caractérisent avant tout par le souci grandissant des différentes nations européennes de s'approprier les marchés américains. Ce que confirmait d'ailleurs Louis XIV en 1709 : «Le principal objet de la guerre présente [de succession d'Espagne] est celui du commerce des Indes et des richesses qu'elles produisent ${ }^{79}$. " Afin d'y parvenir le commerce français a adopté plusieurs attitudes. Dans la courte période de calme qui a suivi la paix de Ryswick (1697), certains exportateurs malouins se sont évertués à reprendre la voie de Cadix et à utiliser la Carrera. Au contraire, derrière Danycan, les plus dynamiques ont tenté une pénétration des colonies espagnoles. On relève, que de mars 1698 à décembre 1701, 17 navires des bords de Rance ont bénéficié de commissions de complaisance pour pratiquer le commerce interlope à destination de la Terre Ferme ${ }^{80}$. Toutefois, avec l'intronisation de Philippe V au trône d'Espagne, le gouvernement français a modifié son attitude et il a exigé de commercer par Cadix, voire d'aider militairement les vaisseaux espagnols de la Carrera.

Ceci n'a pas modifié l'attitude de Danycan qui se savait soutenu par le contrôleur général Chamillart. Il a donc armé quatre frégates en toute illégalité pour l'Amérique au cours de l'année $1703^{81}$ : une pour la Mer du Nord, les trois autres pour la Mer du Sud. Les cargaisons étaient estimées à 1,6 million de livres et les principaux négociants malouins avaient été associés à ces expéditions. Comment expliquer ce changement d'attitude? Si la Carrera, en dépit d'un contexte défavorable, s'est prolongée pendant la guerre de succession d'Espagne (1701-1714) ${ }^{82}$, les risques du commerce sont apparus trop grands à la plupart des négociants malouins. Depuis une descente anglo-hollandaise à Puerto Santa Maria et après le désastre de Vigo (1702), la place andalouse n'offrait plus guère de sûreté. Au contraire, le retour des frégates expédiées vers la Mer du Sud rapportant 7 millions de livres incitait à prolonger le trafic illégal ${ }^{83}$.

André Lespagnol signale que de 1698 à 1724131 navires français ont fréquenté les rivages américains du Pacifique : 84 navires dépendaient de sociétés à direction malouine, 23 d'autres armements portuaires, 24 d'armements parisiens ${ }^{84}$. Entre 1701 et 1715 , les profits moyens ont fréquemment dépassé les $100 \%$. Les différences de rapport observables entre les

78. LesPagnol, André, Messieurs de Saint-Malo..., op. cit., p. 510.

79. GIRARDET, baron de, La correspondance de Louis XIV avec Michel Amelot, ambassadeur à Madrid, Nantes, 1864.

80. Arch. dép. d'Ille-et-Vilaine, 9B 168.

81. Arch. nat., Marine, $\mathrm{B}^{3} 132$.

82. MorineaU, Michel, Incroyables gazettes..., op. cit., p. 311-312.

83. Lespagnol, André, Messieurs de Saint-Malo..., op. cit., p. 531, 637.

84. Ibidem, p 555. 
expéditions interlopes résultaient d'un engorgement du marché. Au-delà de 1715 les résultats ont été généralement déficitaires. Toutefois, d'après Carlos Daniel Malamud Rikles, ce trafic aurait rapporté plus de 54 millions de pesos aux négociants français entre 1701 et $1725^{85}$, ce que montre le graphique suivant.

\section{Retours monétaires vers la France}

(source : MALAMUD RIKLES, Carlos, Daniel, Cádiz y Saint-Malo en el comercio colonial peruano (1698-1725), Cádiz, 1986, p. 67)

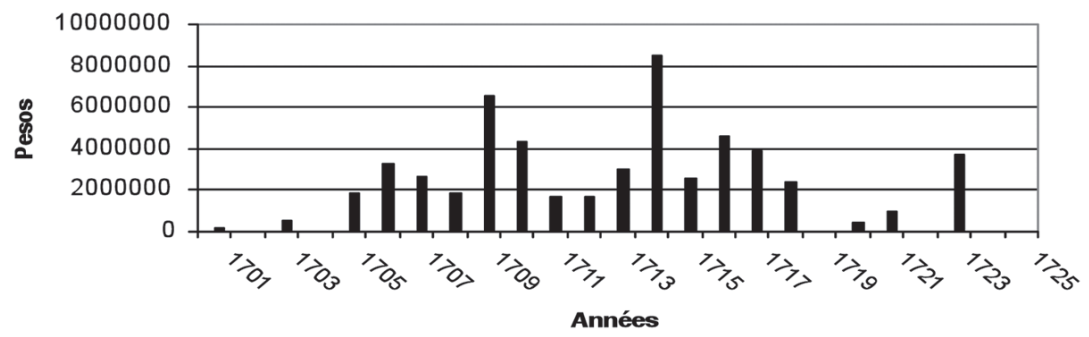

Pour parvenir à de tels résultats le commerce malouin s'est profondément modifié. Sa responsabilité ne s'est plus limitée au seul armement des navires, les armateurs sont devenus propriétaires des cargaisons. Les marchés lointains de la Mer du Sud engageaient des niveaux d'investissement élevés et la traditionnelle division du capital d'un navire en parts ne pouvait plus suffire pour entreprendre ces expéditions lointaines et coûteuses. Sous la forme de billets d'intérêt, de 3000 à 60000 livres, il a donc été fait appel à des capitaux extérieurs, au point que La Lande Magon pouvait écrire : "Ceux de Paris, Lyon, Rouen y ont les plus grandes portions ", concluant toutefois " nous en sommes bien les décideurs".

Il importe aussi de s'interroger sur la nature des cargaisons embarquées. L'arrestation de six navires contrebandiers français sur les côtes du Pérou en 1717 apporte une réponse ${ }^{86}$. S'il convient de signaler que certaines denrées avaient déjà été vendues avant l'interception des contrevenants, l'inventaire qui suit semble toutefois respecter la part des toiles embarquées.

85. Malamud Rikles, Carlos, Daniel, Cádiz y Saint-Malo en el comercio colonial peruano (1698-1725), Cádiz, 1986. Les retours monétaires en France devaient s'effectuer aux hôtels des monnaies. Ceci a été facilité par un cours supérieur à celui du marché libre (Arch. nat., $\mathrm{G}^{7}$ 1687). Par la suite les armateurs malouins ont pris le parti de sous-estimer au moins $50 \%$ des retours, (Arch. nat., $\mathrm{G}^{7} 193$ ).

86. Malamud Rikles, Carlos, Daniel, Cádiz y Saint-Malo..., op. cit., p. 304-343. 
Arrestation de navires contrebandiers français sur les côtes du Pérou

\begin{tabular}{|c|c|c|c|}
\hline $\begin{array}{l}\text { Valeur des } \\
\text { cargaisons }\end{array}$ & $\begin{array}{l}2463585 \\
\text { piastres }\end{array}$ & $\begin{array}{c}\text { Pourcentage } \\
\text { des toiles }\end{array}$ & $\begin{array}{l}\text { Pourcentage des } \\
\text { différentes toiles }\end{array}$ \\
\hline $\begin{array}{r}\text { Toiles bretonnes } \\
\text { bretagnes } \\
\text { pontivys } \\
\text { morlaix et crées }\end{array}$ & $\begin{array}{c}493037 \\
13590 \\
113370 \\
565998\end{array}$ & 22,29 & 51,58 \\
\hline $\begin{array}{r}\text { Autres toiles } \\
\text { rouens } \\
\text { cambrays } \\
\text { cholets } \\
\text { platilles } \\
\text { lins }\end{array}$ & $\begin{array}{l}396796 \\
58840 \\
54825 \\
10439 \\
10410\end{array}$ & 16,10 & 36,16 \\
\hline Valeur des toiles & 1097309 & 44,54 & \\
\hline
\end{tabular}

En effet, les tissus destinés à la Mer du Sud représentaient 44,54 \% de la valeur des cargaisons. Le commerce interlope prolongeait donc celui qui avait pu être observé par Patoulet, trente ans auparavant. Une remarque toutefois, si l'on retrouvait les mêmes productions qu'en 1686, les toiles bretonnes, et en particulier les bretagnes, étaient devenues prépondérantes dans la constitution des "emplettes". Bien que les sources régionales soient peu prolixes sur leur croissance exceptionnelle au cours de cette période, on dispose cependant de quelques informations la concernant. Caillaud, inspecteur des manufactures, pouvait écrire en 1715 : «Depuis deux années [les bretagnes ordinaires] ont augmenté considérablement si bien que celles de 15 sols [l'aune] sont venues à 30 [sols] ${ }^{87}$. " Ultérieurement il analysait la quantité de bretagnes contrôlées par le bureau de Saint-Malo, estimant que leur nombre était passé de 3000 balles en 1714 à 4405 balles en $1719^{88}$. Le recensement des tisserands quintinais relevait 604 ouvriers en 1710 , ils n'étaient que 428 en $1703^{89}$. Comme la demande malouine s'est prolongée, elle a provoqué une forte augmentation du prix des toiles dans la manufacture, au point que l'aune ordinaire valait 2 livres 8 sols en 1719 .

Les " coups de Cobija et d'Arica " qui ont vu l'arrestation de navires contrebandiers français marquent la fin des tentatives provinciales de commercer directement avec le Pérou ${ }^{90}$, même si quelques expéditions ont encore eu lieu après ces désastres. Les pertes estimées à 2,8 millions de piastres en 1717 ont sonné le glas des grandes expéditions vers la Mer du Sud et le retour aux voies traditionnelles du commerce par Cadix.

87. Arch. dép. d'Ille-et-Vilaine, 9B 165.

88. Arch. dép. de Loire-Atlantique, C 660.

89. Arch. mun. de Quintin, HH 2.

90. Malamud Rikles, Carlos, Daniel, Cádiz y Saint-Malo..., op. cit., p. 168. Les arrestations de contrebandiers français à Cobija et Arica ont concerné un navire rouennais et cinq frégates malouines. 


\section{Trois décennies agitées, 1720-1750}

Puisque la Mer du Sud était désormais interdite aux Malouins, ceux-ci sont revenus, comme le souhaitait le gouvernement espagnol, au commerce traditionnel par Cadix. Toutefois, ainsi que l'a montré Michel Morineau ${ }^{91}$, les affaires d'Amérique semblent alors avoir été moins lucratives qu'au cours des périodes précédentes.

\section{Dates des expéditions vers l'Amérique et retours monétaires}

\begin{tabular}{|l|c|c|c|c|c|}
\hline Périodes & $\begin{array}{c}\text { Flottes } \\
\text { (Veracruz) }\end{array}$ & $\begin{array}{c}\text { Azogues } \\
\text { (Veracruz) }\end{array}$ & $\begin{array}{c}\text { Galions } \\
\text { (Terre } \\
\text { Ferme) }\end{array}$ & $\begin{array}{c}\text { Registres } \\
\text { (Buenos } \\
\text { Aires) }\end{array}$ & $\begin{array}{c}\text { Retours } \\
\text { Monétaires } \\
\text { (millions de } \\
\text { piastres) }\end{array}$ \\
\hline $1720-1725$ & $\begin{array}{l}1720 \\
1723\end{array}$ & $\begin{array}{l}1722 \\
1724\end{array}$ & $\begin{array}{c}1721 \\
1723\end{array}$ & 1722 & 48 à 53 \\
\hline $1726-1730$ & 1729 & $\begin{array}{l}1728 \\
1730\end{array}$ & 1730 & 1728 & 57 à 76 \\
\hline $1731-1735$ & 1732 & 1733 & & 1733 & 44 à 47 \\
\hline $1735-1740$ & & 1736 & & 1736 & 43 à 47 \\
\hline
\end{tabular}

Si le commerce de Cadix pouvait parfois procurer de bons rapports, il présentait souvent un caractère aléatoire, ainsi que le Malouin, Magon de la Balue ${ }^{92}$, le signalait en 1724 : « Les comptes de la dernière flotte rendent bien mal pour les toiles, à peine en tire-t-on son argent. " Il est vrai que, pour la Nouvelle-Espagne, les foires de 1724, 1727, 1733 et 1736 se sont révélées peu attractives. Il importe aussi de considérer qu'entre 1715 et 1726 , le gouvernement français en s'alliant avec celui de Londres a nui aux intérêts de ses propres négociants. Ils l'ont fait savoir en 1728 , à l'occasion du congrès de Soissons, reprochant à l'Angleterre son privilège de l'Asiento et puis, surtout, son commerce interlope qui excluait les toiles françaises des marchés de Terre Ferme. Ces doléances semblent avoir été entendues par le cardinal Fleury, celui-ci rétablissant la paix avec l'Espagne en 1729. Bien que certaines critiques aient pu paraître justifiées, l'exportation de toiles bretagnes vers l'Espagne demeurerait importante au début de la période. On relève en effet que 3562 balles avaient été expédiées en $1723^{93}$ et 4226 en $1724^{94}$. Dans cette optique, les jugements formulés à l'égard des Anglais concerneraient plutôt une importante réduction des bénéfices réalisés dans

91. MorineAu, Michel, Incroyables gazettes..., op. cit., p. 360, 361 et 368.

92. SÉE, Henri, « Esquisse de l'histoire du commerce français à Cadix et dans l'Amérique espagnole au XVIII ${ }^{\mathrm{e}}$ siècle ", Revue d'Histoire Moderne, 1928, t. 3, n 13, p. 13-31.

93. Arch. nat. $\mathrm{F}^{12} 1370$.

94. Ibid., F $\mathrm{F}^{12} 1417$. 
le commerce transatlantique qu'une forte diminution des exportations françaises. Afin de revenir à la situation antérieure, Magon de la Balue écrivait en 1726 : «Il serait à souhaiter que les Espagnols ne souffrissent plus d'interlope d'aucune nation et que le commerce se fit, comme jadis, par des flottes et galions. " Il oubliait d'ajouter qu'à l'exemple de ses confrères malouins, il ne dédaignait pas de faire embarquer ses " emplettes " sur tout navire quittant l'Espagne, quand il ne vendait pas directement aux Anglais ou à leurs intermédiaires. Pour preuve, la venue à Saint-Malo de cet Écossais qui, en 1725, avait acheté pour 300000 livres de toiles bretagnes ${ }^{95}$. Les marchands de toiles des environs de Quintin portaient eux aussi une part de responsabilité dans le discrédit de leurs produits, puisqu'ils mélangeaient dans leurs balles des tissus de qualités différentes, voire provenant dans d'autres régions ${ }^{96}$.

Il importait de réagir face à une situation difficilement acceptable, ce sera le règlement du 19 février 1736 concernant les toiles bretagnes ${ }^{97}$. Avec la nouvelle législation, la responsabilité des tisserands dans la fabrication d'une toile était clairement affirmée puisque dix-sept articles de ces lettres patentes les concernaient. Si la mainmise des marchands et bourgeois locaux sur le commerce local était affirmée, il leur était cependant demandé de placer sur l'enveloppe de protection des balles leurs nom et signe de vendeur, ainsi que la qualité et la longueur des toiles exportées. Enfin l'application de ce nouveau règlement était confiée à un sous-inspecteur des manufactures en résidence à Quintin qui exerçait aussi sa surveillance sur les marchés d'Uzel et de Loudéac.

Alors que tout semblait prédisposer le commerce breton à conserver sa prééminence, les rapports se dégradèrent entre l'Angleterre et l'Espagne. Afin de réduire le commerce interlope entretenu avec la Terre Ferme, le gouvernement espagnol décida, en 1735, de remplacer le système de la Carrera par des navires de registres. C'était interdire le "vaisseau de permission " que les Anglais utilisaient à chaque départ des escadres espagnoles. Dans ces conditions, seul un conflit armé pouvait régler cette nouvelle situation : il éclata en 1739.

L'interruption du commerce interlope anglais pouvait favoriser l'exportation des toiles françaises, mais une suite de perturbations a touché la Bretagne. C'est ainsi que les récoltes de lin y ont été catastrophiques de 1740 à 1742, plongeant la zone toilière dans le plus grand dénuement. Le syndic de Quintin pouvait alors écrire : "La cessation presque entière du commerce des toiles, [par manque de lin] unique ressource de cette ville a réduit un si grand nombre dans l'indigence que la plus grande partie pour ne pas dire la totalité sont dans la mendicité ${ }^{8}$. " Analysant la situation qu'avait connue la manufacture en ces tristes années, l'inspecteur provincial des manufac-

95. Arch. nat., $\mathrm{F}^{12} 72$.

96. B.n.F, fr 21788 , fol. 118 et 140 .

97. Arch. mun. de Quintin BB 22 et Arch. dép. d'Ille-et-Vilaine, 10 Bb/378.

98. Arch. mun. de Quintin, BB 22. 
tures, de Coisy ${ }^{99}$, y ajoutait deux autres handicaps. Il signalait d'abord que " la cherté des grains qui régnait aussi [...] avait causé une misère si affreuse dans l'ouvrier qu'il fut obligé d'aller chercher son pain de ville en ville ", puis rappelait qu'en raison des épidémies qui résultaient de cette pénible situation "plusieurs paroisses de l'évêché de Saint-Brieuc où cette fabrique est située perdirent un tiers de leurs habitants ${ }^{100}$ ". C'est dans ce triste contexte que survint, en 1744, la déclaration de guerre de la France à l'Angleterre. Jusqu'en 1748, année où le conflit s'est terminé, les récoltes de lin ont été satisfaisantes en Bretagne, mais l'envoi de toiles à Cadix s'est cependant avéré quasi impossible. Pendant quatre ans, les Malouins ont donc dû faire appel à des navires appartenant à des nations neutres ${ }^{101}$. Toutefois, comme le constatait amèrement de Coisy, le faible tonnage de ces embarcations palliait difficilement le handicap à l'exportation que rencontrait la manufacture où l'aune de toile large ne valait plus alors que 2 livres 5 sols.

Le retour de la paix et la demande de toiles qui s'en est suivi ont alors provoqué leur renchérissement dans la manufacture, au point que l'aune de bretagnes larges est passée de 2 livres 8 sols, en 1749, à 3 livres en 1750 et 4 livres 6 sols en 1751. De Coisy n'attribuait pas cette augmentation aux seuls besoins des colonies espagnoles, mais aux exportateurs européens qui avaient été conduits à ne pas faire rentrer leurs capitaux d'Amérique durant le conflit. En une période plus calme, ils pouvaient reprendre leurs traditionnelles spéculations grâce au système des registres. Ces nouvelles liaisons assuraient un trafic régulier avec l'Amérique et, surtout, un retour rapide du produit des ventes. L'inspecteur attribuait aussi la hausse qu'il observait dans la manufacture à l'intrusion de capitaux parisiens dans le commerce local ${ }^{102}$. C'est ainsi que 5308 balles de toiles avaient été

99. Arch. dép. d'Ille-et-Vilaine, C 3929.

100. Arch. dép. des Côtes-d'Armor, $129 \mathrm{~J}$.

Mercuriales du marché de Loudéac (prix de la perrée [50 kg] en livres et sous)

\begin{tabular}{|c|c|c|c|c|}
\hline Années & Froment & Seigle & Avoine & Blé noir \\
\hline 1737 & 17,10 & 8,17 & 7,04 & 10 \\
\hline 1738 & 19,02 & 8,16 & 7,04 & 9,06 \\
\hline 1739 & 22,10 & 11,04 & 9 & Non coté \\
\hline 1740 & 22 & 16,10 & 13 & Non coté \\
\hline 1741 & 29 & 16,10 & 12,12 & 22 \\
\hline 1742 & 28 & 12,07 & 11,10 & Non coté \\
\hline 1743 & 14,10 & 5,10 & 6,02 & 8,8 \\
\hline
\end{tabular}

101. Sur 1379 balles de toiles bretagnes exportées depuis Saint-Malo et Morlaix en 1746, 938 balles avaient été embarquées sur des navires hollandais, 29 sur des danois, 15 sur des hambourgeois, TANGUY, Jean, "La production et le commerce... ", op. cit., p. 42-45. 102. À ce propos le marchand quintinais, Baron du Taya, pouvait toujours écrire en 1774 : "Le commerce des toiles bretagnes a acquis depuis quelques années la fatale réputation de faire des fortunes rapides. Les étrangers, c'est-à-dire les capitalistes éloignés de la manufacture, y ont déversé beaucoup de fonds pour faire des achats considérables. Ils ont établi de cette façon une concurrence d'achat qui a considérablement augmenté le prix de la toile" (Archives privées, M. de Bagneux). 
exportées en 1748 et 5782 en 1750; comme chaque balle coûtait au moins 800 livres, en deux ans la manufacture des bretagnes avait donc accru ses chiffres de vente de plus de 1500000 livres.

\section{1-1788, de la suprématie à l'effondrement}

À l'inverse des périodes précédentes, on dispose, grâce au travail des différents inspecteurs des manufactures, d'une véritable étude statistique concernant l'exportation de toiles bretagnes entre 1751 et $1788^{103}$, ce que montre le graphique ci-dessous :

\section{L'exportation des toiles bretagnes de 1751 à 1788}

(Source : TANGUY, Jean, "La production et le commerce des toiles bretagnes du XVI au XVIII siècle ", Actes du Quatre-vingt-onzième Congrès National des

Sociétés savantes, Paris, 1969, p. 138-139)

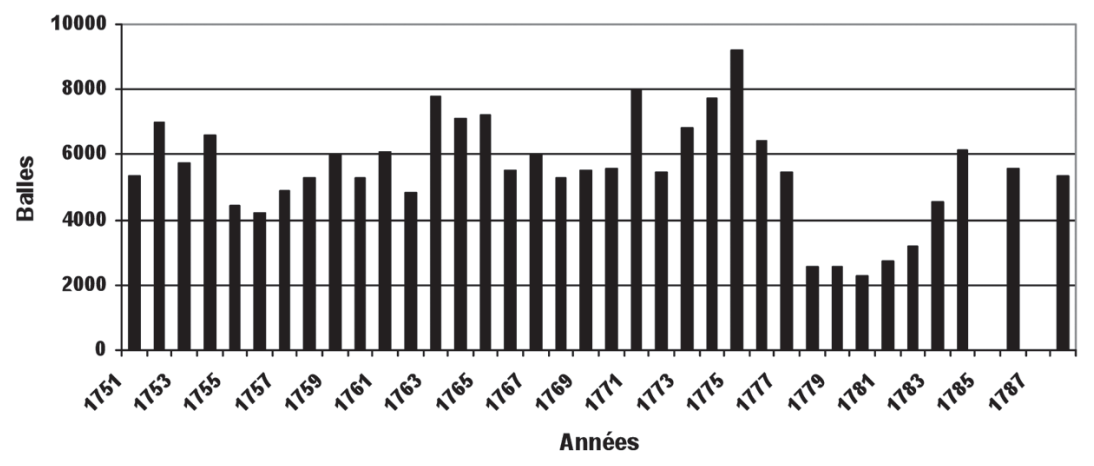

La première caractéristique de ces histogrammes fait apparaître une très grande variabilité dans le nombre de balles contrôlées. Ces fluctuations correspondent surtout aux besoins exprimés par le marché gaditan et aux embarquements prévus pour l'Amérique. Jusqu'en 1754, la réussite commerciale était souvent liée à la chance de pouvoir faire embarquer des toiles sur les navires de registre, situation difficilement maîtrisable par la monarchie espagnole qui a favorisé le retour aux Flottes ${ }^{104}$. Toutefois, les dernières expéditions ne présentaient pas le même intérêt, leurs rotations étant plus longues. Avec le départ des vaisseaux, Cadix tombait dans un état d'hibernation économique, l'argent s'y faisait rare, à moins qu'un navire de registre ne vînt apporter quelque consolation ${ }^{105}$. Si le pouls de Cadix battait au rythme de cette navigation transatlantique, les fluctuations

103. TANGUY, Jean, " La production et le commerce... ", loc. cit., p. 138-139.

104. Le système des Flottes a été repris en 1757, 1760, 1765, 1768, 1772, 1776, 1780 et 1785.

105. "Ce gros secours va faire sans doute meilleures les affaires sur notre place " indiquait le gaditan Barrère en 1761 (Archives privées, descendants Boschat). 
enregistrées en Andalousie se prolongeaient jusqu'en Bretagne ${ }^{106}$. Toutefois l'intérêt espagnol pour les productions bretonnes ne s'est pas démenti de 1751 à 1775 . Au cours de cette période, 153039 balles de bretagnes ont été acheminées vers Cadix, soit une moyenne annuelle de 6121 balles.

L'abondante correspondance commerciale de Mathurin Boschat, l'un des plus importants négociants de la manufacture des bretagnes, apporte des informations complémentaires concernant la zone de production ${ }^{107}$. On découvre tout d'abord la montée en puissance de quelques marchands locaux comme Boschat, de même que celle des divers membres de la famille Glais (Saint-Thélo), de leurs cousins Le Deist (Saint-Hervé et Uzel), de Baron du Taya (Quintin), de Moizan (Trévé), de la fratrie Viet (La Motte et Plouguenast), des Veillet-Dufrêche ${ }^{108}$ (Moncontour). Constituant des alliances temporaires, ces marchands ne sont plus apparus comme les intermédiaires obligés des Malouins, ils ont à leur tour constitué des " emplettes " qu'ils commercialisaient dans les différents ports bretons, à Cadix, en Amérique. On a même vu les Le Deist et les Veillet ouvrir leur maison de commerce à Cadix.

Parmi les nombreuses associations commerciales auxquelles participaient ces différents intermédiaires, arrêtons-nous sur Boschat. En 1753, de concert avec les Surcouf de Saint-Malo, le banquier parisien Darcy et les gaditans Sobia Vande et Cie, ses achats ont représenté 156 balles de toiles estimées 69712 livres. On relève encore qu'entre 1758 et 1766, Boschat ${ }^{109}$, momentanément installé à Saint-Malo ${ }^{110}$, était membre d'une nouvelle société qui regroupait le banquier parisien de Moirie, les négociants Brissac et Perrier-Dubignon de Saint-Quentin et de Laval, les gaditans de SommerVan Reckem. Les diverses spéculations qui ont alors été conduites semblent avoir procuré de substantiels bénéfices, comme en 1765 et $1766^{111}$. Homme prévoyant, Boschat a toutefois su mettre un terme à sa collaboration avec ce groupe, juste avant la faillite de la maison andalouse. Enfin, aidé de ses facteurs (acheteurs intermédiaires), il exerçait un travail de fourmi auprès des différents capitaines de navires qui sortaient de la cité corsaire; ceux-ci se voyaient confier le commerce d'une balle de toile sous l'appellation de "pacotille ", en échange de $10 \%$ des bénéfices.

106. DoRnIC, François, " Le commerce des Français à Cadix d'après les papiers d'Antoine Granjean (1752-1754)", Annales ESC, 1954, p. 311-327.

107. Archives privées, descendants Boschat.

108. Archives privées, M. de la Brosse pour la famille Veillet-Dufrêche.

109. Parmi les achats réalisés dans la manufacture par l'intermédiaire de Boschat, ceux de 1759, 1760 et 1761, s'élevaient à 14000 livres, 74000 livres, 50000 livres.

110. Boschat payait 135 livres pour sa capitation et 70 livres pour son imposition au $20^{\mathrm{e}}$ du commerce et de l'industrie.

111. Cela lui a permis, entre autres, d'acheter la seigneurie d'Uzel au marquis Emmanuel de Durfort de Duras, le 19 novembre 1759, devant Maîtres Gougeon et Le Nouvel, notaires à Saint-Malo. Le prix de cette acquisition s'élevait à 330400 livres, somme à fournir " en lettres de change sur Paris ». On relève aussi qu'à l'occasion du mariage de ses trois filles avec des membres de la noblesse locale, chacune disposait d'une dot de 50000 livres. 
Deux épisodes du long conflit maritime franco-anglais qui a marqué le XVII ${ }^{\mathrm{e}}$ siècle, la guerre de Sept Ans (1756-1763) et la guerre d'Indépendance des États-Unis d'Amérique (1775-1783) ont influé sur le volume des exportations bretonnes, ce que transcrivent les histogrammes précédents.

Dès le 24 février 1755, dans la correspondance régulière que l'avocat rennais Moy du Breuil et Boschat échangeaient, le premier avisait le second des risques de conflit avec l'Angleterre. Il ajoutait le 23 juillet : « Les navires de Saint-Malo ne partiront pas de sitôt. " Comme au cours des conflits précédents, la survie de la manufacture n'a été obtenue que par une fréquentation régulière des ports bretons par des navires neutres. Aussi, à l'occasion d'envois à la maison de Sommer-Van Reckem de Cadix, Boschat a-t-il utilisé des prête-noms comme l'Espagnol Troquero ou les Hollandais Babut et Núñez. Mais à son tour l'Espagne est entrée dans le conflit, et le blocus anglais s'est appliqué à ce royaume. Quelques tentatives par voie de terre ont bien été tentées, mais elles s'avéraient trop onéreuses.

Le port de Saint-Malo qui avait repris ses armements corsaires pour résister au blocus dont il était victime a subi, par deux fois, des coups de main anglais ${ }^{112}$. Entre le 4 et le 11 juin 1758, 14000 soldats britanniques placés sous les ordres de Malborough ont investi Cancale, Paramé et SaintServan. Les destructions de cette troupe ont dépassé les trois millions de livres. Une nouvelle tentative menée par les 5000 hommes du général Bligh a eu lieu du 4 au 11 septembre de la même année. La réponse militaire conduite par le duc d'Aiguillon et jointe à une levée en masse des milices locales a limité cette fois les pillages, sans pour autant nuire grandement à l'envahisseur.

Le deuxième conflit a aussi été précédé par une période d'incertitude. Dès 1775, année qui correspond au plus important envoi de toiles bretagnes avec 9216 balles, le Quintinais Baron du Taya ${ }^{113}$ pouvait écrire à son correspondant gaditan Béhic : «Soyez assuré que si la guerre d'Amérique n'est pas suivie d'une paix cette année, vous verrez les colonies anglaises se déclarer indépendantes et se mettre sous la protection de la France et de l'Espagne qui ne manqueront pas de venger leurs pertes [de la guerre de Sept Ans] et d'affaiblir l'Angleterre »; et d'ajouter en 1777 : «On augmente en France les armements de marine et il y a beaucoup à parier qu'on en fera usage. " Effectivement, alors qu'en cette année 5434 balles de toiles bretagnes avaient transité par les principaux ports bretons, elles n'étaient plus que 2653 en 1778, 2576 en 1779, 2299 en 1780. Il faudra attendre 1784 pour retrouver le niveau moyen d'exportation d'avant 1775 .

Le commerce des toiles bretagnes, après 1779 , a subi un coup encore plus rude que ceux que lui portaient régulièrement les frégates anglaises. Jusqu'alors ces importations devaient acquitter en Espagne des droits

112. Sur la stratégie anglaise au cours du XvIII siècle, une nouvelle perception du conflit est présentée par Lagadec, Yann et PerReon, Stéphane, La bataille de Saint-Cast (Bretagne, 11 septembre 1758). Entre histoire et mémoire, Rennes, 2009.

113. Archives privées, M. de Bagneux. 
de douane variant de 3 à $5 \%$, tandis que celles de Silésie étaient soumises à une taxe de $10 \%$. À la faveur des événements politiques, Frédéric de Prusse obtint que les productions françaises fussent imposées au même tarif que les siennes. Cette demande fut bien accueillie par la cour d'Espagne qui souhaitait se libérer de sa dépendance économique envers la France ${ }^{114}$. Avec ces nouvelles conditions, comme les productions armoricaines étaient d'un coût supérieur de $15 \%$ à leurs concurrentes, les exportateurs gaditans ont privilégié les achats de toiles prussiennes. Dix ans plus tard, les cahiers de doléances de la Bretagne centrale se faisaient toujours l'écho des difficultés de commercialisation que rencontraient leurs tissus à Cadix.

\section{La disparition de la manufacture 1789-1830}

\section{Les causes externes}

Même si, de 1793 à 1815, de très rares ouvertures vers l'Espagne ont pu apparaître, comme après 1796 ou avec la paix d'Amiens (1802), l'essentiel de cette phase se caractérise par une faiblesse des relations commerciales traditionnelles. L'année 1793 marque d'ailleurs le retour du fils Veillet-Dufrêche à Moncontour et la disparition de sa maison de commerce à Cadix ${ }^{115}$. Ultérieurement, la destitution du roi d'Espagne jointe à l'intervention militaire des troupes napoléoniennes a suscité un sentiment anti-français dans la péninsule et provoqué la destruction des produits importés. Bien que des tentatives d'exportation directe vers le Mexique et l'isthme de Panama aient été réalisées depuis Bordeaux, les quelques navires utilisés ne pouvaient rivaliser avec le flux commercial atlantique. De plus, le blocus maritime anglais empêchait toute sortie des rouliers malouins. Il est vrai que le théâtre de leurs exploits corsaires se situait désormais dans l'océan Indien et non plus dans l'Atlantique.

En ce qui concerne la manufacture, les inventaires après décès de quelques marchands disparus au cours de ces tristes années font état de dizaines, voire de centaines, de balles de toiles toujours conservées à leurs domiciles ${ }^{116}$. Ces tissus qui n'avaient pu trouver leurs acheteurs traditionnels ont connu, par l'intermédiaire de colporteurs, un début de commercialisation sur le territoire français. Il faut aussi prendre en compte la situation régionale : la levée en masse de 1793 et la contestation provinciale qui l'a accompagnée ont réduit le nombre des ouvriers de la manufacture d'au moins un tiers ${ }^{117}$. La guerre civile qui est apparue a provoqué une désorganisation des circuits traditionnels, que ceux-ci aient concerné les liaisons avec la zone d'approvisionnement en lin ou le port exporta-

114. ZYLBERBERG, Michel, Une si douce domination..., op. cit.

115. Archives privées, M. de la Brosse.

116. Archives privées de l'auteur déposées aux Arch. dép. des Côtes-d'Armor.

117. Martin, Jean, La Région de Loudéac de 1770 à 1800, thèse de $3^{\mathrm{e}}$ cycle, université de Rennes 2, 1982. 
teur ${ }^{118}$. L'insécurité locale s'est singulièrement aggravée lorsque les habitants des campagnes ont été soumis aux exactions des bandes chouannes. En juillet 1795, Quintin a été investi et rançonné par l'" Armée rouge " qui venait prolonger sur la côte nord un débarquement anglo-émigré auquel Hoche avait mis un terme dans le Morbihan. On relève aussi qu'en 1796 une bande de voleurs, "l'armée des barbouillés ", sévissait dans la région d'Uzel et qu'au même moment, le groupe de Dujardin faisait régner la terreur dans les environs de Loudéac. La misère qui s'était abattue sur la région suscitait des actions violentes. Après 1802 la région a retrouvé un certain calme, mais la situation économique n'a guère été modifiée. Les conditions de vie déplorables de la population ont provoqué un début d'émigration. Ces départs ont pris deux formes, l'une vers les principales villes de la province, l'autre vers l'armée avec les " achats d'hommes " pour le service militaire ${ }^{119}$. Un rapide sondage du solde naturel concernant la plupart des communes qui fréquentaient les marchés aux toiles de Loudéac et d'Uzel s'avère négatif pour la période 1801-1810.

De tous les désagréments que la manufacture a connus, il convient également de prendre en considération la disparition des grands négociants malouins, car ils avaient été, au cours des phases précédentes, les moteurs du développement de la manufacture des bretagnes. Il importe de rappeler l'action du représentant en mission Le Carpentier à Saint-Malo. Si sa répression n'a pas égalé celle de Carrier à Nantes, elle s'est cependant révélée néfaste pour les puissantes familles de négociants qu'abritait la cité corsaire ${ }^{120}$. Les plus aisées ont été pressurées financièrement, et les plus compromises par leurs alliances nobiliaires ont été exécutées. Au cours de la période impériale, l'impossibilité d'armer des navires a définitivement détourné du commerce maritime ceux qui avaient survécu à la période révolutionnaire ${ }^{121}$.

La seconde Restauration a laissé croire, un moment, que la fin des guerres napoléoniennes allait rouvrir les ports espagnols aux productions de la manufacture. Cette illusion s'est rapidement effondrée devant les nouvelles réalités politiques et économiques. Dès le 5 août 1817, Jean-Marie Morice, marchand de toiles bretagnes et maire d'Uzel, constatait amèrement que les "brouilleries des Amériques " avaient considérablement

118. Ibidem, " Justice, parole, violence en Bretagne-Centrale de 1790 à 1802 », Mémoires de la Société d'émulation des Côtes-d'Armor, t. 129, 2000, p. 65-100.

119. Ibid., "Quand les Bretons se vendaient 1801-1855 ", Mémoires de la Société d'Émulation des Côtes-d'Armor, t. 128, 1999, p. 175-203.

120. HeRPIN, Émile, Saint-Malo sous la Révolution 1789-1800, Rennes, 1931. Cet auteur évoque p. 183-184 l'arrestation puis la disparition des armateurs Magon de la Blinais et de Grandclos Meslé. Au domicile du premier, outre de l'argent, il avait été trouvé 380 balles et 6 ballots de toiles bretagnes. Des perquisitions ont été aussi menées au domicile des autres membres de la famille Magon, chez les de la Lande, de la Ville Huchet, de Coëtisac, de la Ballue. Brachet, Le conventionnel J.-B Le Carpentier (1759-1829), Paris, 1912.

121. BENAERTS, Louis, "Saint-Malo pendant le Consulat et l'Empire ", Annales de Bretagne, 1899 , p. 367-401. 
ralenti les exportations et provoqué une forte baisse des prix ${ }^{122}$. Mais le plus terrible était à venir. De 1816 à 1821, l'Argentine, le Chili, le Mexique et le Pérou ont accédé à l'indépendance et se sont fermés aux productions bretonnes. Cette nouvelle situation conduisait le conseil d'arrondissement de Loudéac à faire connaître aux autorités supérieures le " grand état de souffrance " qui s'était abattu sur la manufacture ${ }^{123}$. En effet, alors que 3000 balles de toiles avaient pu encore être exportées en 1825, l'année suivante ce chiffre tombait à 1000. C'en était désormais fini des liens traditionnels qui avaient si longtemps uni la manufacture à l'Espagne et, plus encore, à l'Amérique latine.

\section{Les causes internes}

Au sein même de la manufacture des bretagnes on trouvait des raisons à son effondrement. La dispersion des lieux de culture du lin, de tissage et d'exportation, loin d'unir le Trégor, la Bretagne centrale et Saint-Malo en une unité de production, a favorisé les fonctions intermédiaires parasites et surenchéri les productions.

Parmi les autres éléments à prendre en compte, il faut évoquer l'imperfection des méthodes de travail ainsi que les outils utilisés par les différents ouvriers et ouvrières. Le maire de Quintin ${ }^{124}$ écrivait à ce sujet en 1811 : "Dans la manufacture des bretagnes [...] la fabrication est aux mains du peuple [...] Comment attendre dans cette position, non seulement le perfectionnement des outils, mais même un bon assortiment de la matière de fabrication. " La chambre consultative d'Uzel ${ }^{125}$ constatait en 1824 : "Aucune mécanique ne s'est introduite parmi nous, si on excepte des métiers à navettes volantes. " Encore convient-il de signaler que bien plus tard, en 1855, sur les 1559 métiers à tisser toujours en activité dans les communes de la manufacture, seuls 299 disposaient de cette amélioration ${ }^{126}$.

Cependant les causes décisives de la disparition de la manufacture nous semblent devoir être recherchées dans le groupe des marchands. S'il existe bien des dynamiques favorables à la réussite des entreprises commerciales, il en est d'autres qui engourdissent l'activité, voire favorisent son déclin. Cette situation a été clairement perçue par les contemporains Geslin de Bourgogne et de Barthélémy ${ }^{127}$. Ils considéraient, en effet, que la manufacture était " tombée parce que ceux qui la dirigeaient ayant fait leur fortune n'ont pas voulu subir les embarras de la transformation de la filature et du tissage à la main en procédés mécaniques ". Il est vrai qu'à

122. Arch. dép. des Côtes-d'Armor, $129 \mathrm{~J}$.

123. Arch. dép. des Côtes-d'Armor, $1 \mathrm{~N} 8$.

124. Arch. dép. des Côtes-d'Armor, 9M 7.

125. Arch. dép. des Côtes-d'Armor, 9M 7.

126. GAUTIER, Élie, Tisserands de Bretagne, Morlaix, 1988, p. 82.

127. Ibidem, p. 73. 
la différence de ce qui se passait à Laval et à Cambrai ${ }^{128}$, où finalement les marchands s'étaient imposés grâce au verlagsystem, leurs confrères des trois principaux marchés de la manufacture pratiquaient le kaufsystem. Quoique certains marchands de la Bretagne centrale aient participé à la grande aventure malouine, la plupart n'étaient qu'un petit relais face aux exportateurs du grand port. Bien que les plus hardis aient pu apparaître riches au sein d'une zone particulièrement pauvre, beaucoup ne disposaient pas des capitaux suffisants pour s'intégrer aux grandes compagnies qui dominaient alors le commerce vers Cadix $^{129}$. Il importe enfin de prendre en compte la psychologie particulière de ce groupe social. Sa réussite s'est concrétisée localement par l'édification de résidences somptueuses, par des alliances matrimoniales orientées vers les possesseurs d'offices, vers les maîtres du sol. Tout cela a donc conduit à favoriser des préoccupations plutôt liées à la rente, c'est-à-dire fort éloignées des objectifs manifestés par des capitaines d'industrie.

128. PIтоu, Frédérique, Laval au XVIII siècle. Marchands, artisans, ouvriers dans une ville textile, Laval, 1995. TERRIER, Didier, Les deux âges de la proto-industrie. Les tisserands du Cambrésis et du Saint-Quentinois, 1730-1880, Paris, 1996.

129. Arch. nat., $T^{*} 1097 / 8$, en 1772, l'emplette constituée par Jean-Joseph de Laborde, ancien banquier de la cour de Versailles, comprenait 71 balles de bretagnes, 17 balles de crées, 25 balles de silésiennes auxquelles s'ajoutaient des balles de soie, des caisses de taffetas et de chapeaux de castor, des ballots de drap d'Elbeuf et de dentelle du Puy, enfin du papier. 


\section{RÉSUMÉ}

Pendant plus de trois siècles, le tissage du lin a constitué l'une des spécificités du centre de la Bretagne. Si, à l'origine, cette production était principalement destinée aux foires castillanes, l'intervention des Malouins et des Vitréens, à la fin du $\mathrm{XVI}^{\mathrm{e}}$ siècle, a permis de pénétrer les marchés de l'Amérique espagnole. Cette nouvelle orientation a provoqué une augmentation des productions régionales et, en 1686, les toiles dites bretagnes représentaient plus du tiers des tissus français exportés vers la péninsule ibérique. Le commerce interlope malouin lié à la guerre de succession d'Espagne et la disparition momentanée du système des flottes et des galions ont été autant de facteurs qui ont favorisé la croissance de la production régionale au cours du xviiie siècle. Toutefois, après 1779 et l'imposition de nouveaux droits de douane sur les importations françaises, la manufacture des bretagnes a connu une crise profonde. Ultérieurement se sont ajoutées les ruptures politiques qui ont affecté les relations franco-espagnoles, de même que l'accession à l'indépendance des colonies d'Amérique latine. Tous ces éléments négatifs ont eu raison d'une activité séculaire et ils ont plongé la zone toilière dans la misère, favorisant les débuts de l'émigration.

\section{ABSTRACT}

For more than three centuries, linen was one of the specialities of Central Brittany. If, at the beginning, this production was destined for fairs in Castile, the involvement of the merchants from Saint-Malo and Vitré, at the end of the 16th century, allowed them to penetrate the markets of Spanish America. This new need entailed an increase in regional production, and, in 1686, cloths called "bretagnes" accounted for over a third of French fabrics exported to the Iberian peninsula. The direct - and somewhat illegal - exportations by the Saint-Malo merchants during the War of the Spanish Succession and the temporary disappearance of "La Carrera de Indias" were two factors leading to the increase of regional production during the $18^{\text {th }}$ century. However, after 1779 and new customs duties on French imports, the "bretagne" manufacture went through a deep crisis. Afterwards came the political ruptures affecting Franco-Spanish relations and the new independence of the Latin American colonies. All these negative elements meant the end of a century old activity and reduced Central Brittany to destitution, leading to the beginning of emigration. 